Research Article

\title{
Numerical Simulation of Interaction between Large-Scale Congestion and Vent during the Natural Gas Explosion in a Kitchen
}

\author{
Lei Pang $\mathbb{D}^{1,2}$ Mengjie Jin ${ }^{1}{ }^{1},{ }^{1}$ Qianran Hu ${ }^{(D)},{ }^{1}$ and Kai Yang $\mathbb{D}^{1,2}$ \\ ${ }^{1}$ School of Safety Engineering, Beijing Institute of Petrochemical Technology, Beijing, China \\ ${ }^{2}$ Beijing Academy of Safety Engineering and Technology, Beijing, China \\ Correspondence should be addressed to Kai Yang; ycyangk@bipt.edu.cn
}

Received 20 April 2021; Accepted 15 July 2021; Published 5 August 2021

Academic Editor: Paolo Castaldo

Copyright (C) 2021 Lei Pang et al. This is an open access article distributed under the Creative Commons Attribution License, which permits unrestricted use, distribution, and reproduction in any medium, provided the original work is properly cited.

\begin{abstract}
The influence of large-scale congestion on a confined natural gas explosion in a typical Chinese kitchen was studied using the computational fluid dynamics technology. It was found that opening the explosion venting surface promotes the development of turbulence, flame propagation velocity, and multipeak overpressure in the explosion flow field. Large-scale congestion can significantly strengthen the influence of the explosion venting surface on the flow field; the congestion and the explosion venting surface have a synergistic effect on the explosion flow field. At the moment of gas explosion, the flow fields in each area of the kitchen exhibit different distribution characteristics. A flow field near small-scale congestion is more likely to produce greater turbulence, combustion rate, and flame speed. The obstruction effect of large-scale congestion perpendicular to the flame propagation direction is dominant. The indoor flame propagation speed and overpressure development speed increase and the peak combustion rate and indoor peak overpressure decrease with an increase in obstacle blockage. Increases in the large-scale volume congestion rate and volume blockage in the kitchen induce changes in the indoor flame propagation mode and increase the external explosion overpressure. This paper investigated the correlation behavior between large-scale congestion and vent surface in a typical Chinese civil kitchen during natural gas explosion process and provided important support for understanding the mechanism of congestion on gas explosion process and the distribution of explosion hazards in a kitchen.
\end{abstract}

\section{Introduction}

As high-quality green energy, natural gas is widely used in industrial production of raw materials and for cooking and heating. With the rapid development of the global economy, the demand for natural gas has increased significantly. However, with the aging of pipelines and the irregular use of gas facilities, gas explosion accidents occur more frequently, with significant casualties and economic losses. According to China News, there were 548 gas explosion accidents in 2020, resulting in 84 deaths and 670 injuries, of which 218 were indoor gas explosion accidents, mostly in kitchens [1]. Vented explosions induced by kitchen doors and windows, coupled with the turbulence of indoor cupboards, cabinets, stoves, and other items causing congestion, promote the development of indoor explosion flow fields and explosion hazards, increasing the complexity of the vented explosion process.

As a general representation of indoor congestion, volume blockage is widely used to study the effects of congestion on explosive flow fields. To theoretically explore the effect of congestion on the acceleration mechanism of gas explosion flames and the influence of explosion hazards, researchers have studied the influence of regularly arranged slender congestion objects with different obstacle blockages on vented explosions. Peter et al. [2] used numerical methods to study the effect of a fixed arrangement of vertical cylinders (with an outer diameter of 2 in, which is $0.0508 \mathrm{~m}$ ) on the vented explosion process of propane gas and found that the indoor peak overpressure increased with an increase 
in obstacle volume blockage. Kuznetsov et al. [3] investigated the influence of vertical wooden beams with lengths of $1 \mathrm{~m}$ and cross-sections of $0.04 \mathrm{~m} \times 0.04 \mathrm{~m}, 0.04 \mathrm{~m} \times 0.05 \mathrm{~m}$, and $0.05 \mathrm{~m} \times 0.05 \mathrm{~m}$ in a regular arrangement on a hydrogen vented explosion in an explosion chamber with dimensions of $1 \mathrm{~m} \times 0.96 \mathrm{~m} \times 0.98 \mathrm{~m}$. The results showed that greater obstacle blockage produced a greater flame combustion speed and overpressure. Using numerical methods, Zhang et al. [4] vertically arranged slender columnar obstacles of different sizes in a room with dimensions of $4.6 \mathrm{~m} \times 4.6 \mathrm{~m} \times 3 \mathrm{~m}$ to study their influence on the vented explosion hazard characteristics of LPG-air mixtures. It was found that the explosion temperature of the LPG-air mixture changed little with obstacle blockage, but the explosion pressure was sufficient to damage brick and mortar walls with a thickness of $370 \mathrm{~mm}$. Lian et al. [5] used numerical methods to study damage to the building structure caused by the explosion of methane, hydrogen, and liquefied petroleum gas (LPG) in the presence of small square columns evenly arranged in a device with dimensions of $4.6 \mathrm{~m} \times 4.6 \mathrm{~m} \times 3 \mathrm{~m}$. It was found that as the obstacle blockage increased from 0.24 to 0.36 , the maximum flight distance of explosive fragments generated by the explosion vent surface increased from $6.18 \mathrm{~m}$ to $18.78 \mathrm{~m}$, with an expansion factor of 3.04. Congestion is an important factor affecting indoor explosion hazards. Tomlin et al. [6] studied the effect of cylinders with a length of $4.5 \mathrm{~m}$ and a diameter of $0.18 \mathrm{~mm}$ on the explosion of natural gas in a $9 \mathrm{~m} \times 4.5 \mathrm{~m} \times 4.5 \mathrm{~m}$ explosion chamber. It was found that the overpressure is caused by flame acceleration resulting from indoor congestion and the explosion venting surface. Under normal circumstances, when the size of the explosion vent is fixed, the indoor peak overpressure increases with increasing obstacle blockage. Some research has studied the influence of obstacle shape on gas explosions. Masri et al. [7-9] studied an explosion chamber with dimensions of $0.195 \mathrm{~m} \times 0.195 \mathrm{~m} \times 0.545 \mathrm{~m}$. The effect of circular, triangular, and rectangular congestion cross-sections on a propane/ air explosion was studied to determine the influence of different obstacle blockages and congestion shapes on the flame shape and speed. For rectangular cross-sections, the volume blockage had a significant effect on flame acceleration; the effect was relatively small for triangular and circular cross-sections.

To determine the explosion hazard characteristics in actual accident scenarios, the influence of gas cylinder congestion on the vented explosion process was studied using actual conditions at a combustible gas cylinder storage site. Schiavetti et al. [10, 11] analyzed the influence of congestion with different cylinder sizes on the hydrogen explosion process with explosive devices of $1.15 \mathrm{~m}^{3}$ and $25 \mathrm{~m}^{3}$. It was found that congestion increases the maximum peak overpressure in the chamber and a larger volume blockage produces a greater flame area and combustion rate. Skjold et al. [12] conducted hydrogen explosion experiments in ISO 20GP containers using gas cylinders for congestion to study the effect of obstacle blockage on a hydrogen-vented explosion; the results showed that the explosion pressure increased with an increase in gas concentration and congestion. However, when the gas concentration increased from $12 \%$ to $15 \%$, the maximum explosion pressure decreased with an increase in obstacle blockage. Chen et al. [13] conducted a hydrogen-air mixture deflagration experiment in a $27 \mathrm{~m}^{3}$ square explosion chamber and studied the effects of gas concentration, explosion venting area, and gas cylinder congestion on vented explosions. It was found that both the peak overpressure and flame velocity increased with an increase in the volume blockage. Li et al. [14] used a $1 \mathrm{~m}^{3}$ rectangular container to study the effect of gas cylinder congestion parallel to the direction of the explosion vent in a hydrogen-air vented explosion. It was found that when the volume blockage increased from 0 to 0.44 , the indoor and outdoor peak overpressures gradually increased and the peak overpressure and peak overpressure arrival time gradually decreased. These studies provide important support and a theoretical basis for understanding the influence mechanism of congestion on the vented gas explosion process and the distribution of explosion hazards. However, the existing research has usually considered only small-scale congestion in regular shapes and uniform arrangements, or the structure of the congestion was simplified, making it difficult to understand the actual accident process to accurately reveal the nature of the explosion hazard. The influence of kitchen congestion characteristics and layout on the explosion flow field is often ignored, especially for gas explosion accidents in residential kitchens. The existing research results are somewhat inadequate for guiding safety design for gas explosion prevention and control in residential kitchens. At the same time, gas explosion may also cause damage to the building structure. Therefore, some scholars [15] have used robust design criteria to conduct related studies on structural damage in order to obtain a more robust seismic design and reduce explosion hazards.

In terms of technical standards, NFPA68 [16] in the United States provides a simplified model for the maximum vented explosion overpressure, which can be used in large spaces with a length-to-diameter ratio not greater than 5 . However, the surface areas of indoor equipment and facilities are omitted when calculating the surface area of the surrounding body, and the enhancement effect of the builtin congestion on the flame is ignored. The European Union EN14994 [17] provides a calculation model for the maximum vented explosion overpressure suitable for explosion chambers with a length-to-diameter ratio not greater than 2 and a volume not greater than $1000 \mathrm{~m}^{3}$. The turbulence enhancement effect in the model is based mainly on the complexity factor assigned to the explosion chamber. The model focuses mainly on small-scale continuous obstacles in industrial plants; the four assignments of complexity factors in the model are not applicable to residential buildings. Although the "Code for Fire Protection Design of Buildings" in China [18] includes vented explosion requirements for industrial plants and warehouses, it does not include vented explosion safety design methods and technical requirements for residential buildings with typical large-scale congestion.

Based on the study of the explosive flow field in a residential kitchen by Yang et al. [19], this study uses computational fluid dynamics technology to further investigate 
the correlation between large-scale congestion and vent surfaces in typical Chinese kitchens during a natural gas explosion and determine the influence of volume blockage on indoor flow field parameters.

\section{Numerical Methods}

2.1. Numerical Models. The computational fluid dynamics (CFD) technique is used to solve the transient flow field in confined space. The model mainly uses the finite volume method to solve a series of equations including the massconservation equation, momentum-conservation equation, and energy-conservation equation. With the help of the Cartesian tensor notation, it can be expressed as follows [20].

The mass-conservation equation is

$$
\frac{\partial \rho}{\partial t}+\frac{\partial}{\partial x_{j}}\left(\rho u_{j}\right)=0
$$

The momentum-conservation equation is

$$
\frac{\partial}{\partial t}\left(\rho u_{i}\right)+\frac{\partial}{\partial x_{j}}\left(\rho u_{j} u_{i}\right)=-\frac{\partial p}{\partial x_{i}}+\frac{\partial \tau_{i j}}{\partial x_{j}} .
$$

The energy-conservation equation is

$$
\frac{\partial}{\partial t}(\rho E)+\frac{\partial}{\partial x_{j}}\left(\rho u_{j} E\right)=\frac{\partial}{\partial x_{j}}\left(\Gamma_{E} \frac{\partial E}{\partial x_{j}}\right)-\frac{\partial}{\partial x_{j}}\left(p u_{j}\right)+\tau_{i j} \frac{\partial u_{i}}{\partial x_{j}},
$$

where $x$ is the space coordinate, $t$ is the time coordinate, $\rho$ is the density, $u$ is the velocity, $p$ is the static pressure, and $i$ and $j$ are the coordinate directions. $E$ is the specific internal energy; its expression is

$$
E=C_{V} T+m_{f u} H_{c}
$$

where $C_{V}$ is the constant-volume specific heat, $T$ is the temperature, $m_{f u}$ is the mass fraction of the fuel, and $H_{c}$ is the heat of combustion. The turbulent-diffusion coefficient is $\Gamma^{*}=\mu_{t} /(\sigma)^{*}$, where $(\sigma)^{*}$ is the default value of the turbulent Prandtl constant. $\tau_{i j}$ is the viscous stress tensor, and its expression is

$$
\tau_{i j}=\mu_{t}\left(\frac{\partial u_{i}}{\partial x_{j}}+\frac{\partial u_{j}}{\partial x_{i}}\right)-\frac{2}{3} \delta_{i j}\left(\rho k+\mu_{t} \frac{\partial u_{i}}{\partial x_{j}}\right),
$$

where the turbulence-viscosity coefficient $\mu_{t}=C_{\mu} \rho k^{2} / \varepsilon$, where $k$ and $\varepsilon$ are the turbulent kinetic energy and its dissipation rate, $\delta_{i j}$ is the Kronecker delta, and the model constant $C_{\mu}=0.09 \mathrm{~m}^{2} / \mathrm{s}$. The turbulence in the vented gas explosion process is described by the standard $k$ - $\varepsilon$ turbulence model. It consists of two conservation equations for $k$ and $\varepsilon$, respectively:

$$
\begin{aligned}
& \frac{\partial}{\partial t}(\rho k)+\frac{\partial}{\partial x_{j}}\left(\rho u_{j} k\right)=\frac{\partial}{\partial x_{j}}\left(\Gamma_{k} \frac{\partial k}{\partial x_{j}}\right)+\tau_{i j} \frac{\partial u_{i}}{\partial x_{j}}-\rho \varepsilon, \\
& \frac{\partial}{\partial t}(\rho \varepsilon)+\frac{\partial}{\partial x_{j}}\left(\rho u_{j} \varepsilon\right)=\frac{\partial}{\partial x_{j}}\left(\Gamma_{\varepsilon} \frac{\partial \varepsilon}{\partial x_{j}}\right)+C_{1} \frac{\varepsilon}{k} \tau_{i j} \frac{\partial u_{i}}{\partial x_{j}}-C_{2} \frac{\rho \varepsilon^{2}}{k}
\end{aligned}
$$

where $C_{1}$ and $C_{2}$ are constants $\left(C_{1}\right.$ and $C_{2}=1.44$ and 1.79). A one-step reaction model is used to describe the combustion process of the fuel/air mixture. This is mathematically formulated as a conservation equation for the fuel mass fraction:

$$
\frac{\partial}{\partial t}\left(\rho m_{f u}\right)+\frac{\partial}{\partial x_{j}}\left(\rho u_{j} m_{f u}\right)=\frac{\partial}{\partial x_{j}}\left(\Gamma_{f u} \frac{\partial m_{f u}}{\partial x_{j}}\right)+R_{f u} .
$$

The volume combustion rate $R_{f u}=C_{t} \rho\left(s_{t}{ }^{2} / \Gamma_{\mathrm{fu}}\right) R_{\mathrm{min}}$, where $R_{\min }$ is the minimum of the mass fractions for fuel, oxygen, and the reaction product, and $C_{t}$ is the combustionmodel constant $\left(C_{t}=40\right)$. The turbulence combustion velocity is expressed as

$$
S_{t}=1.8 u_{t}^{0.412} \cdot L_{t}^{0.196} \cdot S_{l}^{0.784} \cdot v^{-0.196},
$$

where $u_{t}$ is the turbulence intensity, $L_{t}$ is the characteristic length of the turbulence, $S_{l}$ is the specific laminar combustion velocity, and $v$ is the fluid dynamic viscosity.

The effective laminar burning velocity $S_{\mathrm{b}}$ can be expressed as

$$
S_{b}=S_{l}\left(1+F_{S} R_{f}\right)
$$

where $S_{l}$ is the specific laminar combustion velocity, $R_{f}$ is the spherical flame radius, $F_{s}$ is the laminar flame acceleration coefficient, and the value is 0.15 .

2.2. Verification of Grid Independence and Experimental Validation of the Model. The numerical model uses an eightnode structural grid to discretize the space and subgrid technology to describe the effect of small-scale entities on the flow field [21]. The physical model and the scenario simulated in this study is similar to that in [22]. To verify the correctness of the model, explosion overpressures calculated in [22] were compared with the experimental results of Bauwens et al. [23]. The variation trend of the two was similar, which proved the applicability of the numerical method [24]. Meanwhile, the effect of the grid size has been verified also. The grid size $(0.1 \mathrm{~m} \times 0.1 \mathrm{~m} \times 0.1 \mathrm{~m})$ used in this study is same as those in [22].

\section{Research Plan}

Based on the "Design Code for Residential Buildings" [25] and the "National Building Standard Design Atlas-Residential Kitchen" (14J913-2) [26] in China, this study selected an apartment kitchen with a type II structural layout as the research object, as shown in Figure 1. The model kitchen size was set as $3.4 \mathrm{~m}$ (length) $\times 2.1 \mathrm{~m}$ (width) $\times 2.4 \mathrm{~m}$ (height). The layout of the objects in the room and the main simulation parameters are consistent with the description in [22], including the following: the window in Figure 1 was regarded as a square vent with dimensions of $0.8 \mathrm{~m} \times 0.8 \mathrm{~m}$; the lower edge was $1 \mathrm{~m}$ from the floor, and the opening pressure was $20 \mathrm{kPa}$. To accurately describe the impact of an external explosion on the indoor explosion flow field, the calculation domain was extended to five times the length of the room along the direction of the vent. The extended part 


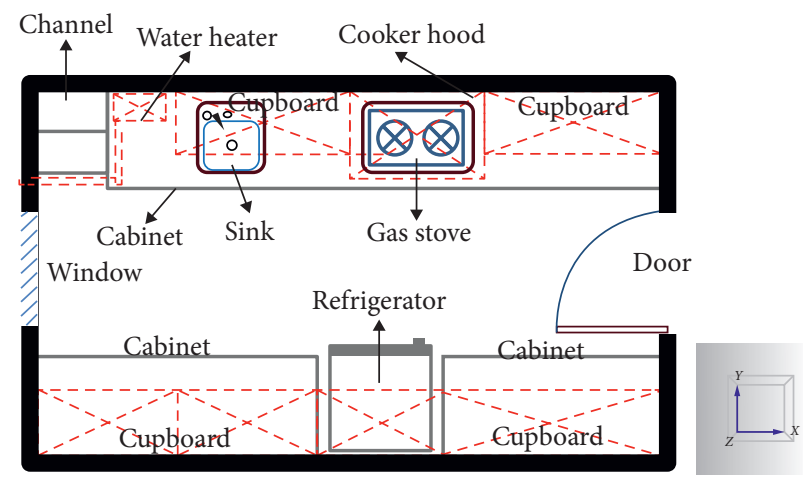

FIgURE 1: Layout of a type II kitchen.

of the calculation domain was set as a free-flow boundary. The calculated domain size was $20.4 \mathrm{~m} \times 2.1 \mathrm{~m} \times 2.4 \mathrm{~m}$, and the total number of grids generated by a grid size of $0.1 \mathrm{~m}$ is 112,750 . The kitchen was filled with premixed methane gas/ air with a volume concentration of $10 \%$ in a static state. The initial pressure and temperature of the environment in the calculation domain were set to $1.01325 \times 102 \mathrm{kPa}$ and $300 \mathrm{~K}$, respectively. A spherical ignition source with a radius of $0.015 \mathrm{~m}$ was placed at the geometric center position, $0.05 \mathrm{~m}$ away from the back wall of the kitchen. A physical model of a type II kitchen is shown in Figure 2. To accurately describe the distribution and sudden changes in the explosion flow field characteristics, several measuring points were set up. Table 1 provides a detailed description of the measuring points.

Based on the type II layout of the kitchen, the core congestion characteristics in the explosion flow field induced by the explosion venting surface were investigated. The volume blockage was changed by changing the size of the cabinet and wall cabinet. The simulation conditions are presented in Table 2.

\section{Results and Discussion}

\subsection{Correlation Mechanism of Vented Explosion Surface and Large-scale Congestion in the Explosion Flow Field}

4.1.1. Turbulence Characteristics. Figure 3 shows the turbulent kinetic energy-time curves at the central location in an airtight room, an empty constrained explosion room, and a typical congested room. The turbulent kinetic energy in the airtight room is maintained at a low level. The turbulent kinetic energy in the constrained room first increases and then decreases with time, but the turbulent kinetic energy in the empty room has a lower growth rate, reaching its peak at approximately $0.6 \mathrm{~s}$. Before the explosion venting surface opens, the turbulent kinetic energy in the congested room is almost unaffected by congestion. The explosion increases rapidly after opening, reaching a peak value at approximately $0.33 \mathrm{~s}$. The indoor peak turbulent kinetic energy with congestion increases by two orders of magnitude compared with the empty room. It is observed that turbulence is weakest in a closed room. The opening of the explosion vent promotes the gas in the room to accelerate outward axially, producing a relatively small turbulence. Although the largescale congestion has little effect on the turbulence, the opening of the explosion vent causes the turbulence of the flow field to increase; the explosion vent and congestion have a synergistic effect on the indoor turbulence.

Figure 4 shows the peak turbulent kinetic energy-distance curves for the three working conditions. The turbulence energy in the closed room is weak. In the empty vent room, opening the explosion vent induces a weak turbulent flow, which is more obvious near the explosion vent. In the congested room, the coupling of congestion with different scale characteristics and the explosion vent induces fluctuations in the indoor turbulence. Small-scale obstacles such as range hoods promote turbulent flow; large-scale congestion objects such as refrigerators hinder gas flow and inhibit turbulent energy.

4.1.2. Combustion Rate and Flame. The turbulence characteristics of the flow field affect the gas combustion rate and flame propagation speed. The variation trend of the indoor peak combustion rate along the axial direction of the room is shown in Figure 5. Figure 6 shows the flame cloud map on the $z=1.5 \mathrm{~m}$ slice for the three working conditions. When there is no congestion, the indoor peak combustion rate curve is almost the same; there is a significant difference near the explosion vent, similar to the turbulent kinetic energy change trend. With congestion, the indoor combustion rate increases earlier and almost linearly. It is also observed in Figure 6 that before the explosion venting surface was opened, the flame structure was hemispherical in the early stage of explosion, and the flame propagation speed was relatively low. With congestion, although the flame passes through congestion objects such as cupboards and cabinets, its forward shape does not seem to change significantly. A possible reason is that large-scale congestion objects are arranged on the edge of the chamber wall, and their arrangement direction is the same as the flame propagation direction; there is not much turbulence on the surface of the congestion. The shape of the flame changed significantly after it passed through the first sudden change in congestion size. In the middle of the flame, an elliptical area appeared where a cloud of combustible gas burned. With increasing time, the flame on the side of the room appeared in a depression area near the water heater with rapid gas burning, caused by the sudden change in the congestion cross-section and rapid turbulent combustion induced by the small-scale water heater.

The variation trend of the flame propagation velocity along the axial direction of the room is shown in Figure 7. The variation trend is similar to that of the peak turbulent kinetic energy, as shown in Figure 4, indicating a positive feedback mechanism between the forward at a relatively stable low speed. The action of the vent surface has little influence on the flame because the opening pressure of the vent surface is $20 \mathrm{kPa}$. With congestion, the change in flame propagation velocity depends mainly on the effect of congestion on the flow field flame propagation and turbulence in the flow field. When there is no congestion, the flame 


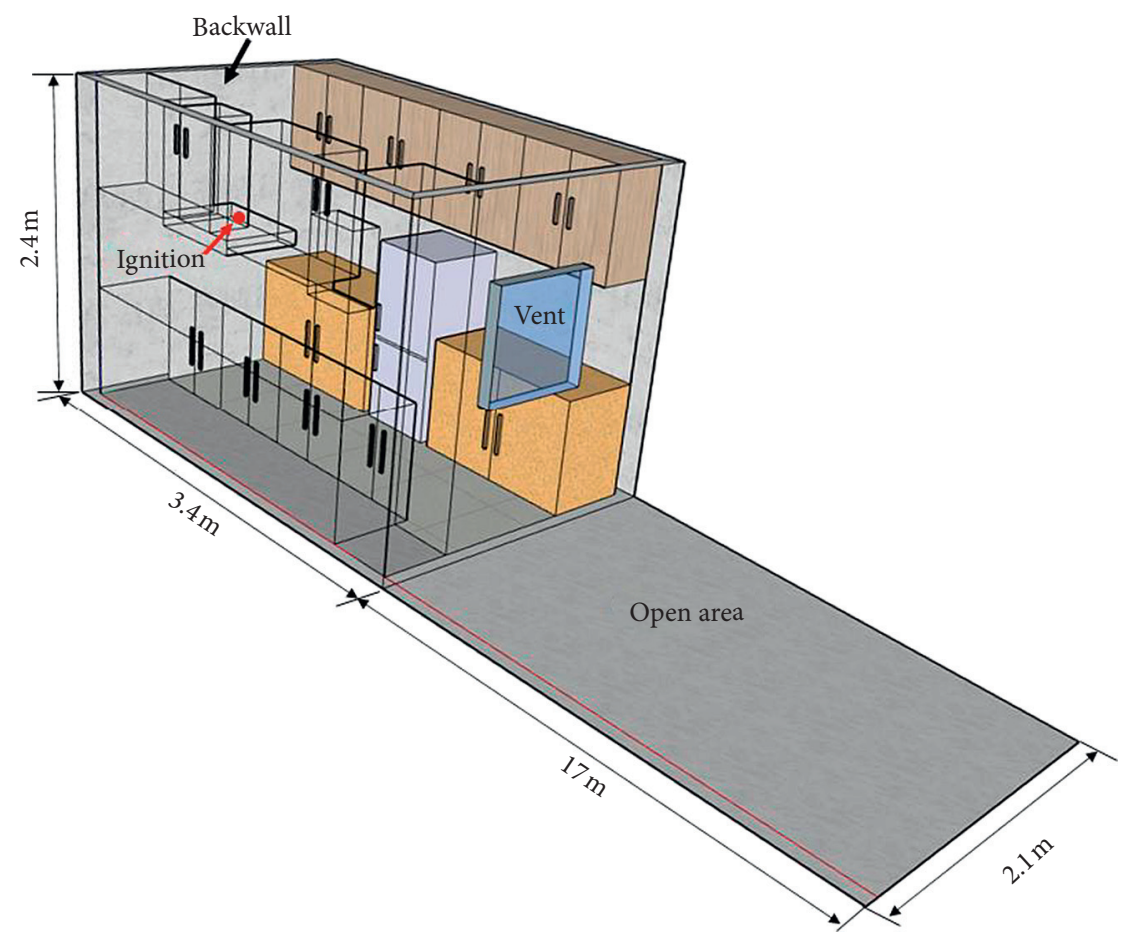

Figure 2: Physical model of a type II kitchen.

TABle 1: Description of measuring points.

\begin{tabular}{|c|c|}
\hline Gauges & Description \\
\hline $1-7$ & Measuring points arranged along the centre line of the explosion vent from $x=0.1 \mathrm{~m}$ at $0.5 \mathrm{~m}$ intervals $(y=1.05 \mathrm{~m}, z=1.4 \mathrm{~m})$ \\
\hline $8-14$ & $\begin{array}{l}\text { Measuring points arranged along the } x \text {-axis in the middle of the wall cabinets on both sides from } x=0.1 \mathrm{~m} \text { at } 0.5 \mathrm{~m} \text { intervals } \\
\qquad(y=1.05 \mathrm{~m}, z=2.1 \mathrm{~m})\end{array}$ \\
\hline $15-21$ & $\begin{array}{l}\text { Measuring points arranged along the } x \text {-axis from } x=0.1 \mathrm{~m} \text { at } 0.5 \mathrm{~m} \text { intervals in the middle of the cabinets on both sides } \\
\qquad(y=1.05 \mathrm{~m}, z=0.4 \mathrm{~m})\end{array}$ \\
\hline $22-28$ & Measuring points arranged along the $x$-axis from $x=0.1 \mathrm{~m}$ at $0.5 \mathrm{~m}$ intervals on top of the row cabinet $(y=0.3 \mathrm{~m}, z=1.4 \mathrm{~m})$ \\
\hline $29-35$ & Measuring points arranged along the $x$-axis from $x=0.1 \mathrm{~m}$ at $0.5 \mathrm{~m}$ intervals under the cupboard $(y=1.8 \mathrm{~m}, z=1.4 \mathrm{~m})$ \\
\hline
\end{tabular}

TABLe 2: Simulation conditions.

No. Cabinet width $(\mathrm{m})$ Cabinet height $(\mathrm{m})$ Cupboard width $(\mathrm{m})$ Cupboard height $(\mathrm{m})$ Opening pressure (kPa) Volume blockage

\begin{tabular}{|c|c|c|c|c|c|c|}
\hline 1 & - & - & - & - & - & 0 \\
\hline 2 & - & - & - & - & 0 & 0 \\
\hline 3 & 0.5 & 0.75 & 0.3 & 0.7 & 20 & 26.04 \\
\hline 4 & 0.5 & 0.85 & 0.3 & 0.8 & 20 & 28.65 \\
\hline 5 & 0.6 & 0.85 & 0.4 & 0.8 & 20 & 33.72 \\
\hline 6 & 0.7 & 0.85 & 0.5 & 0.8 & 20 & 38.88 \\
\hline 7 & 0.7 & 0.95 & 0.5 & 0.9 & 20 & 42.65 \\
\hline
\end{tabular}

propagates [27]. The flame exhibits two stages of propagation with congestion. In the first stage, when the flame interacts with the congestion, the increased flame surface area promotes the flame propagation speed. In the second stage, the flame front and the vortex behind the congestion interact, inducing flame deceleration. This may be due to the unburned gas flowing in front of the flame, causing the convective flame tip to expand and decelerate [28, 29].
4.1.3. Overpressure. The overpressure-time curves of the central measurement points in different rooms are shown in Figure 8 . The pressure development trend in the rooms was almost the same before the explosion venting surface was opened. An increase in pressure is caused by the expansion of combustion products [13]. Unburned gas produces turbulence around congestion [28], and the combustion rate is faster. Thus, the pressure of a congested room increases 


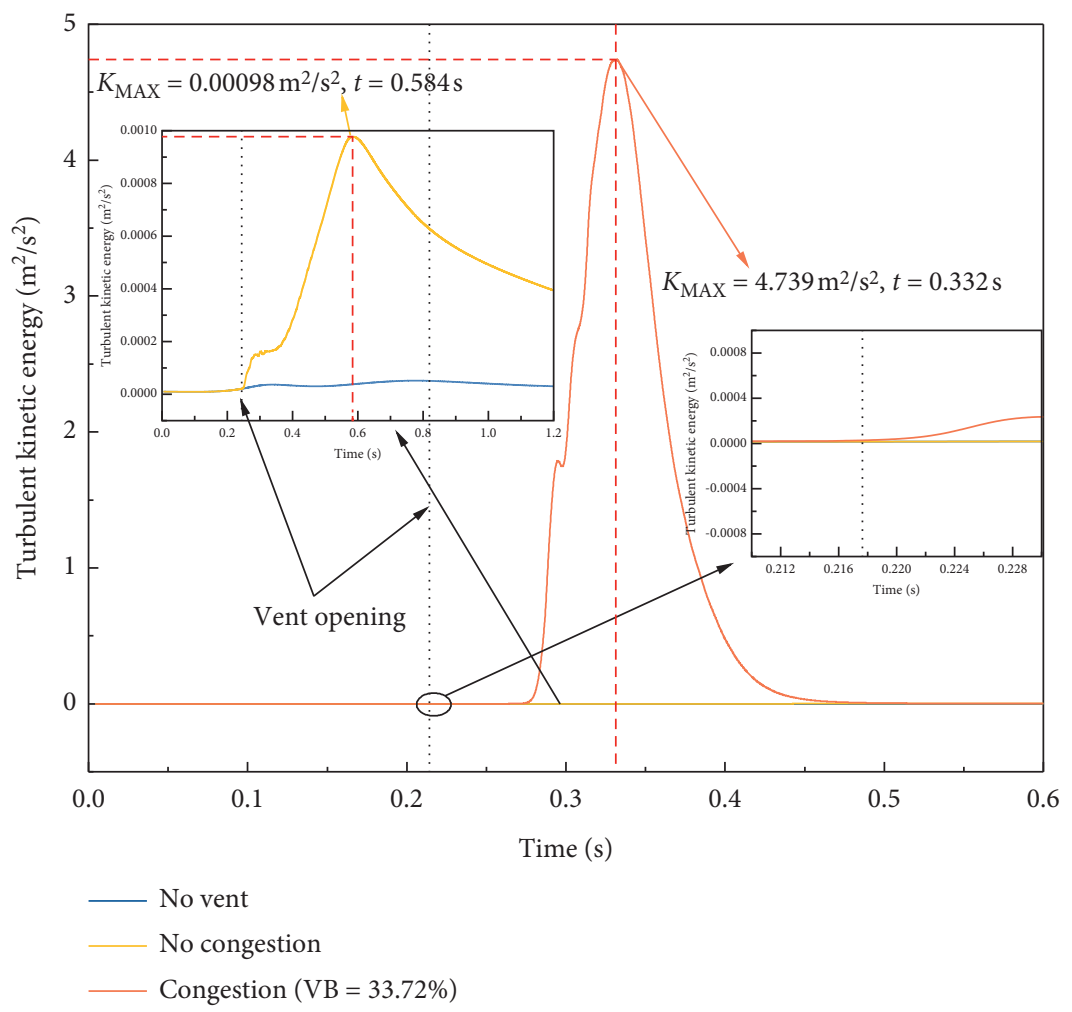

FIgURE 3: Indoor turbulent kinetic energy-time curves for a closed room, an empty room, and typical congestion conditions.

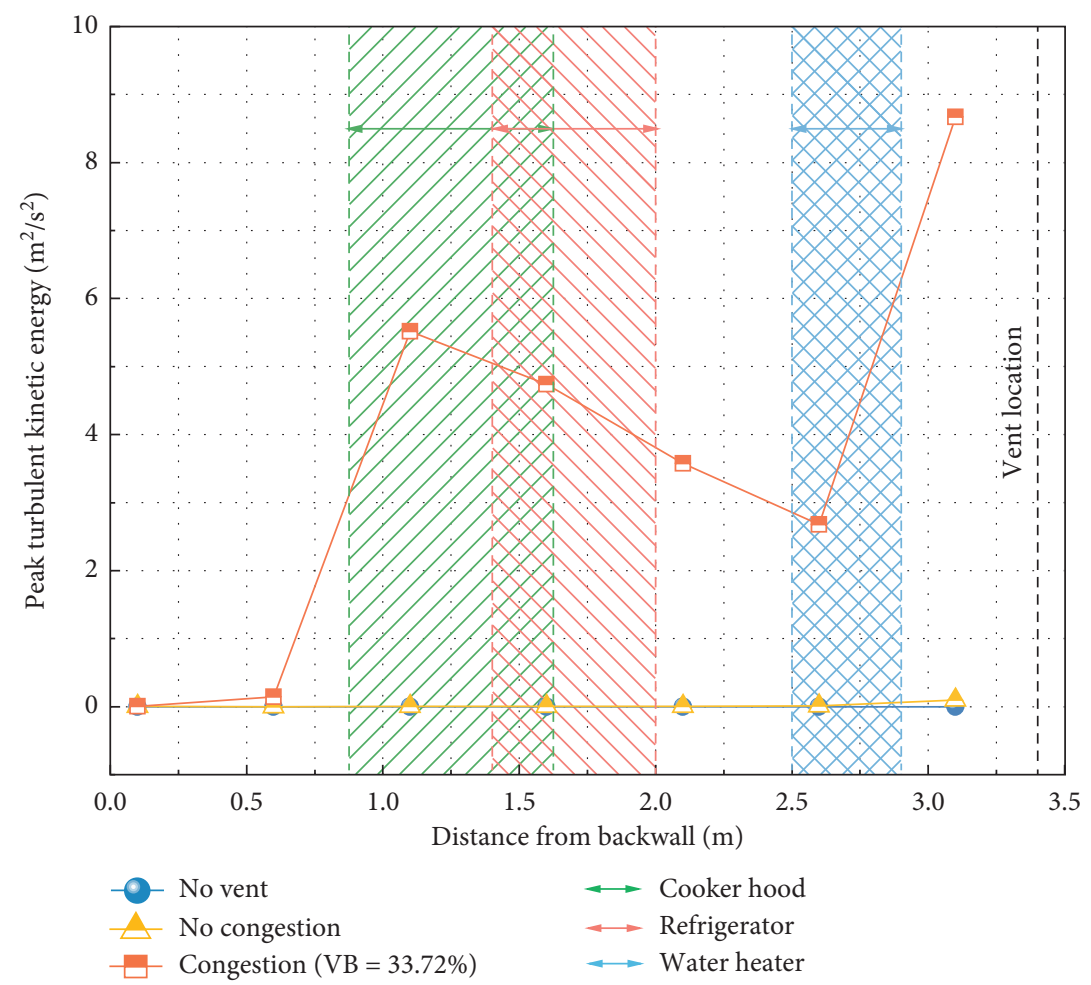

FIGURE 4: Indoor peak turbulent kinetic energy-distance curves for a closed room, an empty room, and typical congestion conditions. 


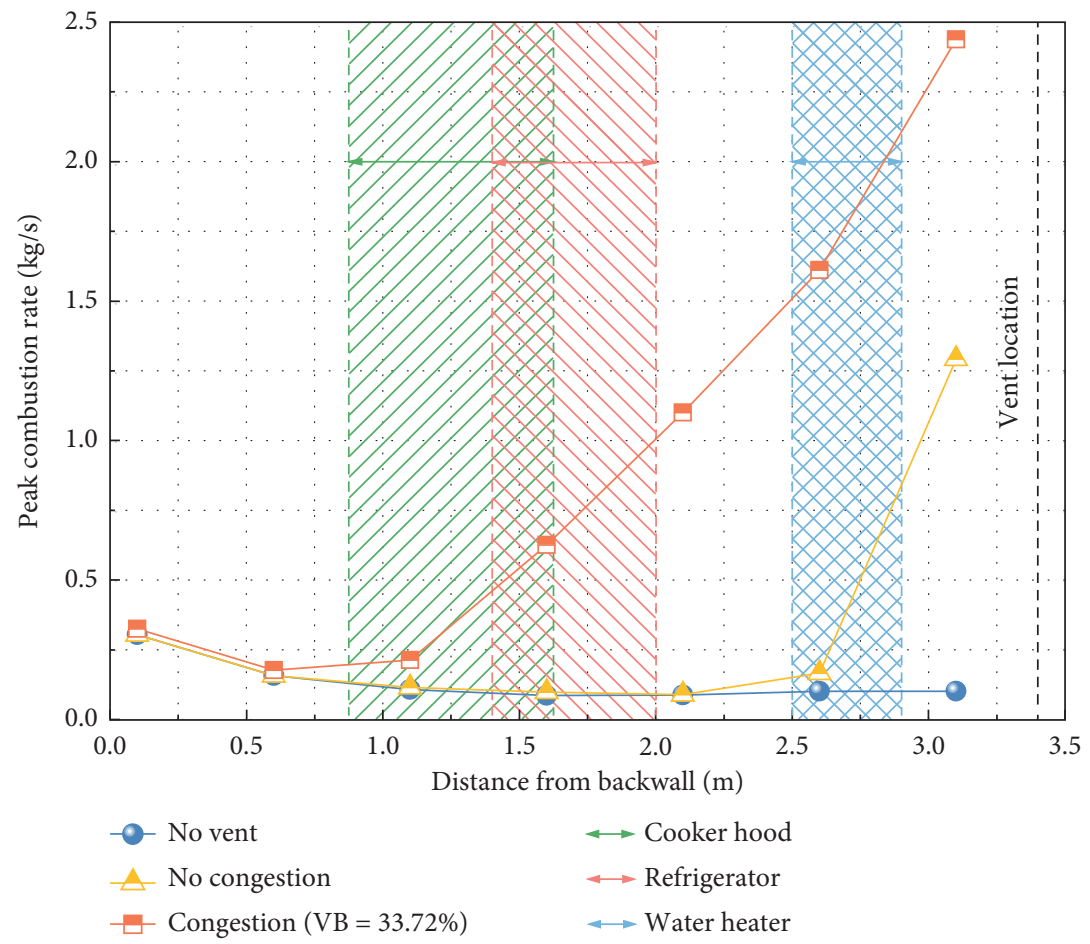

FIgURE 5: Indoor peak combustion rate-distance curve.

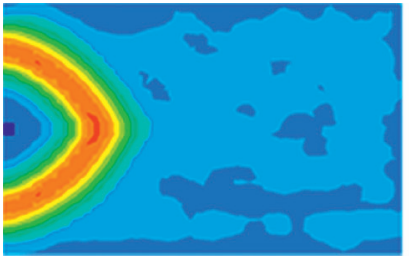

(1) Airtight

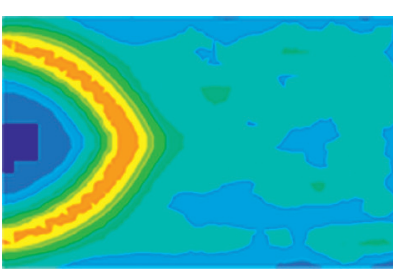

(1) Airtight

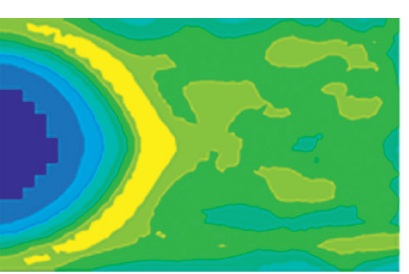

(1) Airtight

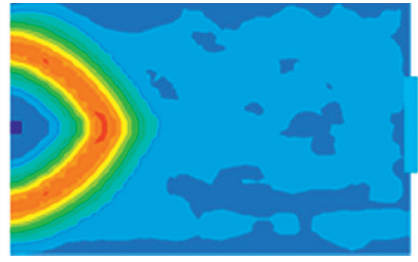

(2) Empty

(a)

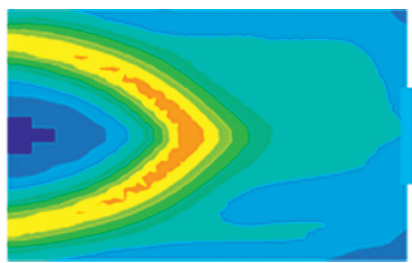

(2) Empty

(b)

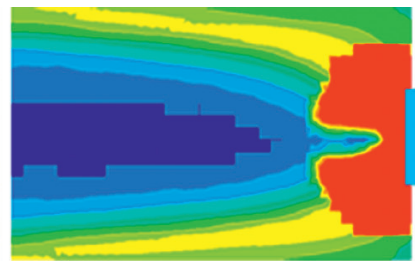

(2) Empty

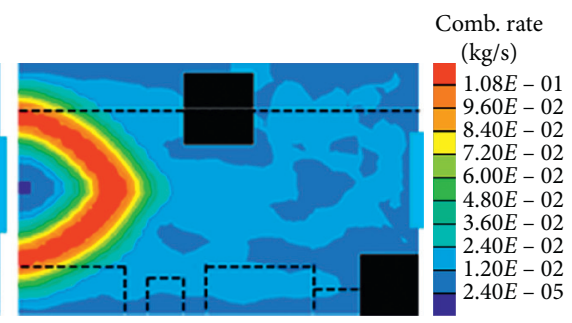

(3) Congestion

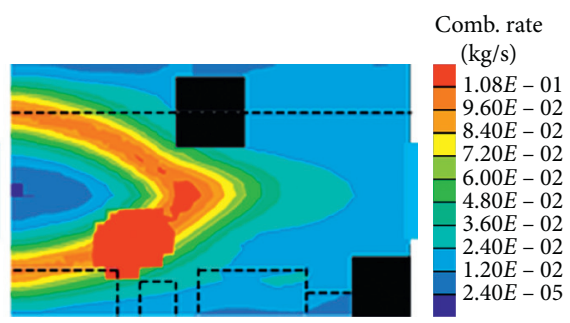

(3) Congestion

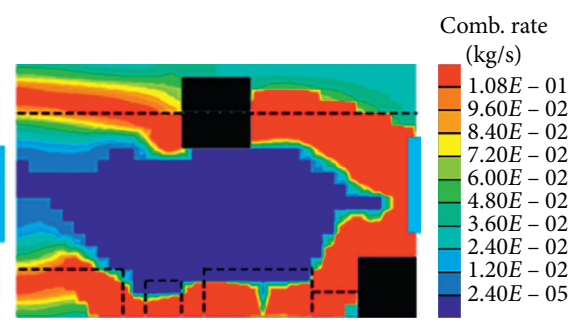

(3) Congestion

(c)

FIGURE 6: Flame cloud map on $z=1.5 \mathrm{~m}$ slice: (a) opening of vent surface; (b) peak combustion rate; (c) maximum flame area. 


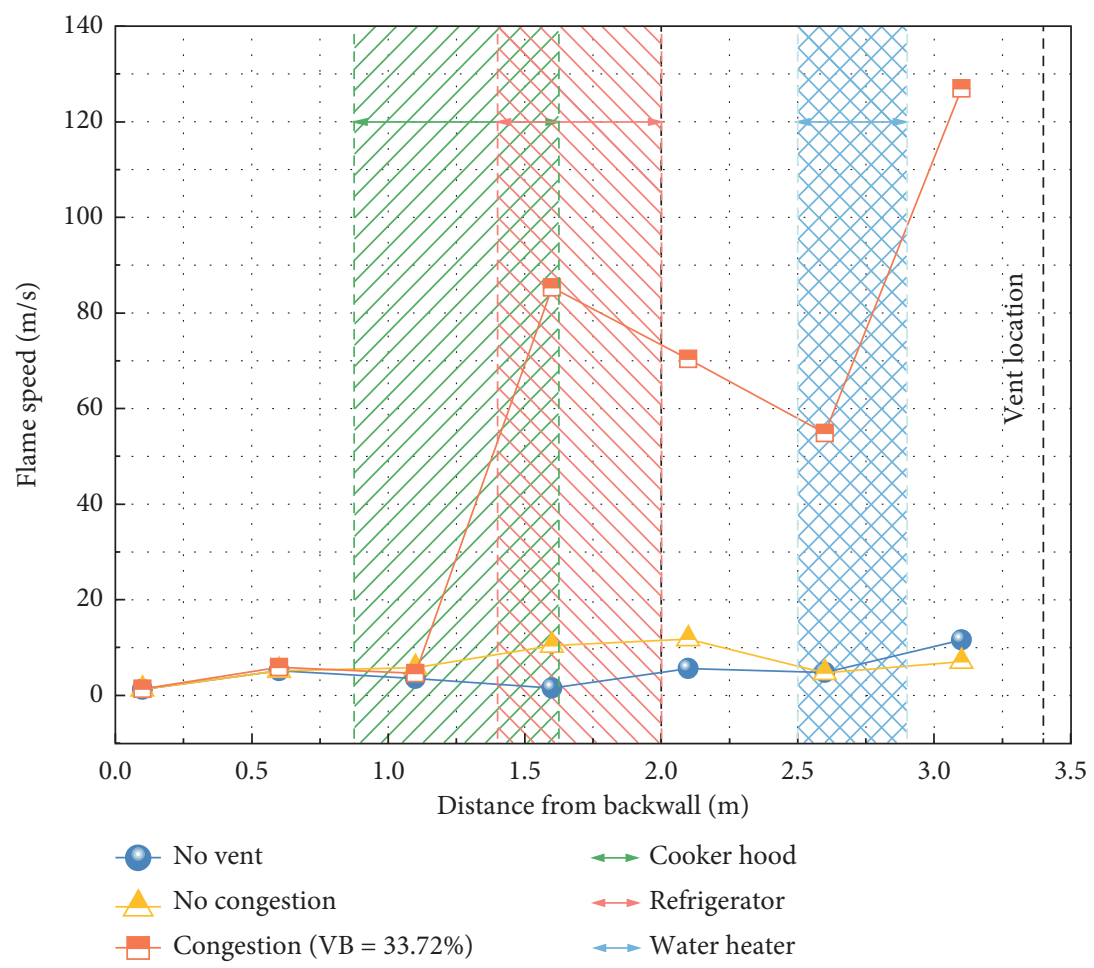

FiguRE 7: Indoor flame propagation speed-distance curve.

faster, and the opening pressure of the explosion vent surface is reached earlier. After the vented explosion surface is opened, a large amount of gas is discharged from the vented explosion port, forming an overpressure peak $P_{1}$. Because the closed room is in an ideal adiabatic environment, the overpressure increases monotonically with time, and there is no energy loss.

The overpressure peak $P_{2}$ may be the result of the combined effect of the peak indoor maximum flame area and the external secondary explosion. Pang et al. [30] also had the same explanation about the relevant content. They thought that when the combustion rate is relatively larger and the peak combustion rate changes rapidly, an external secondary explosion may have occurred. The secondary explosion wave can propagate back into the room and block the vent at the same time; therefore, a stronger external explosion peak appears in the room. Because the turbulence induced by congestion increases the flame area and increases the combustion rate in the room, peak $P_{2}$ is higher and its arrival time is earlier. The pressure increase in the empty room was relatively slow, the peak value was lower, and the peak value was reached later, indicating that congestion has a significant effect on the development of explosive overpressure, especially for the second peak.

Figure 9 shows the peak overpressure-distance curves on the central axis in different rooms. The peak overpressure at each measuring point in the closed room was almost unchanged and much greater than in the other two conditions. The overpressure at each position in the congested room was significantly greater than in the empty room. In the vented explosion room, the peak overpressure near the explosion vent gradually decreased; the overpressure near the explosion vent in the congested room decreased faster than in the other rooms.

\subsection{Dual Effects of Congestion Characteristics on Flow Fields}

4.2.1. Turbulence Characteristics. To study the dual effects of the distribution characteristics of indoor congestion on the explosion flow field, the typical congestion room $(\mathrm{VB}=33.72 \%)$ was divided into five regions to analyze the explosion process, as shown in Figure 10.

The turbulent kinetic energy of the intermediate measuring points on the central axis in different areas of the room changes with time, as shown in Figure 11. The indoor turbulent kinetic energy first increases and then decreases, but the peak value and arrival time in different regions are different due to the difference in congestion distribution. The turbulence kinetic energy in region I is the greatest, followed by region IV. The turbulence kinetic energy in other regions is lower, differing by a factor of more than 150 in peak turbulent kinetic energy. Region IV reaches the peak first and region $\mathrm{V}$ reaches the peak last.

Figure 12 shows the peak turbulent kinetic energydistance curves along the axial direction of the room in different regions. Figure 13 shows the velocity vector distribution on slices at different heights. It is observed that region I is directly opposite the explosion vent and is most affected by it. Opening the explosion vent accelerates the discharge of indoor gas; the gas in this region has a higher flow velocity, causing the flow field turbulence to increase 


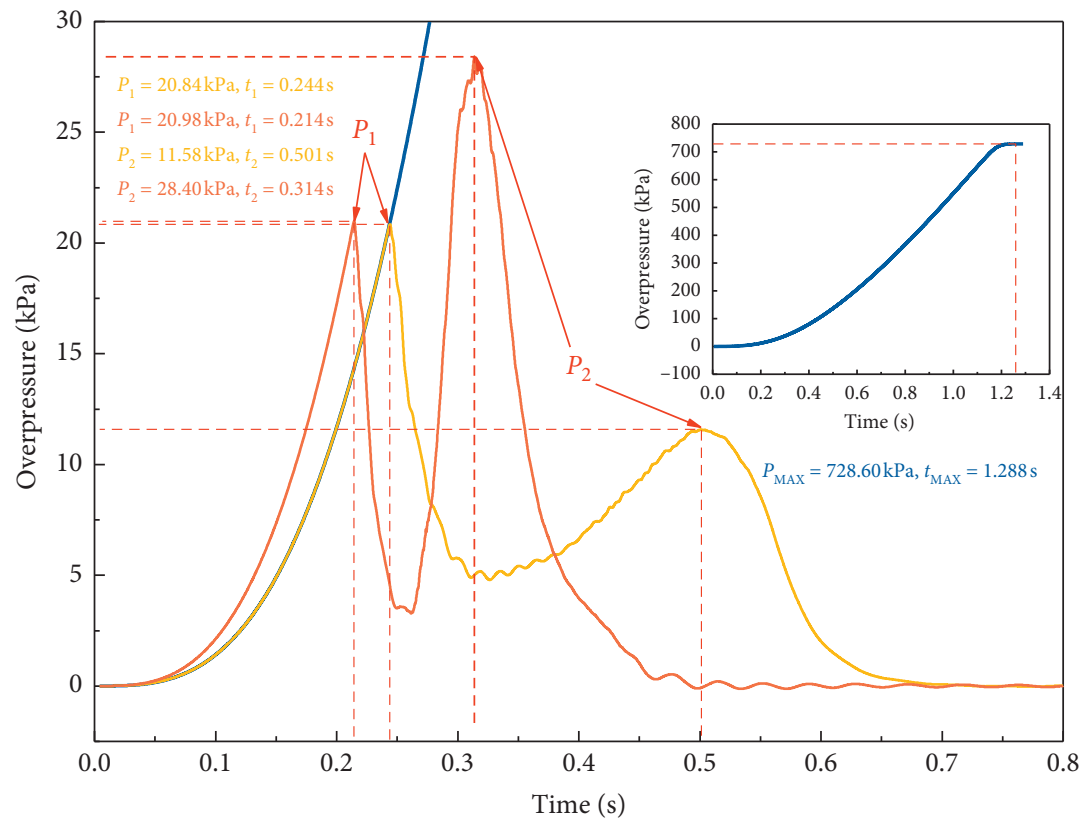

No vent

No congestion

Congestion $(\mathrm{VB}=33.72 \%)$

FIgURE 8: Indoor overpressure-time curve.

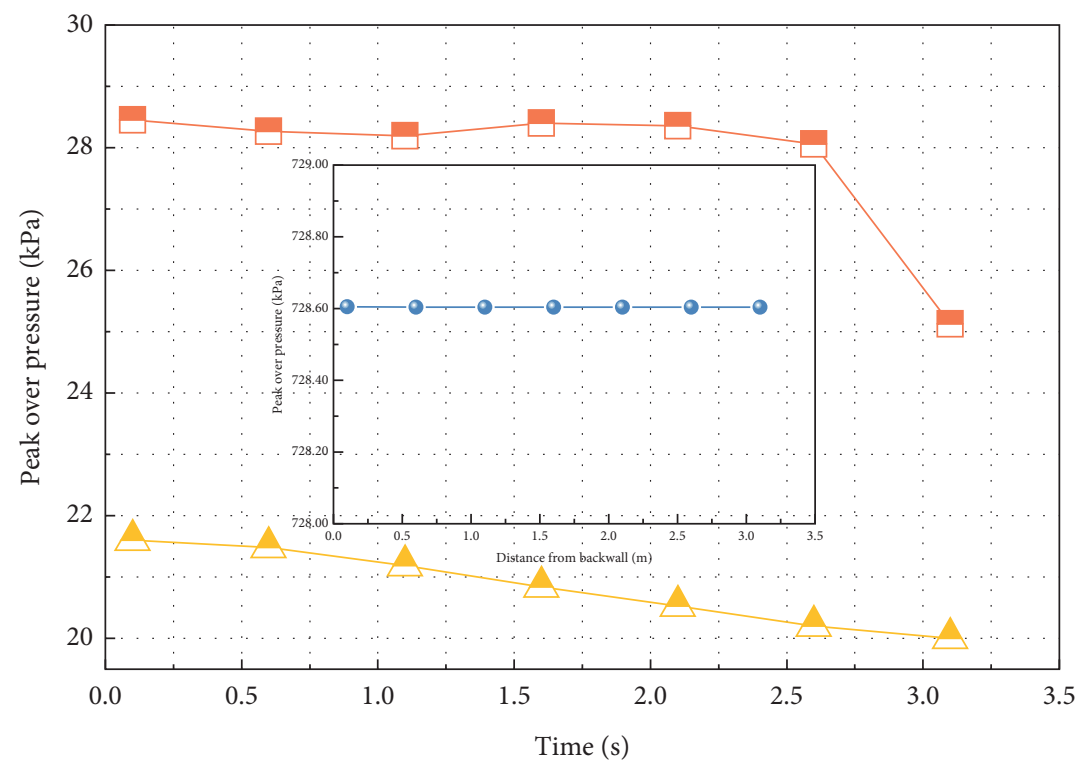

No vent

No congestion

Congestion $(\mathrm{VB}=33.72 \%)$

Figure 9: Indoor peak overpressure-distance curve.

further. The turbulence generated by the small-scale congestion (cooker hood) in region IV also increases the peak turbulent flow energy in region I. Regions II and III are greatly affected by the roof and the ground. In Figures 13(a) and 13(c), it is observed that the gas flow at the front and rear walls is obstructed; reflux occurs, hindering further development of turbulence. The cooker hood in region IV enhances the turbulent flow; the vortex generated by the gas 


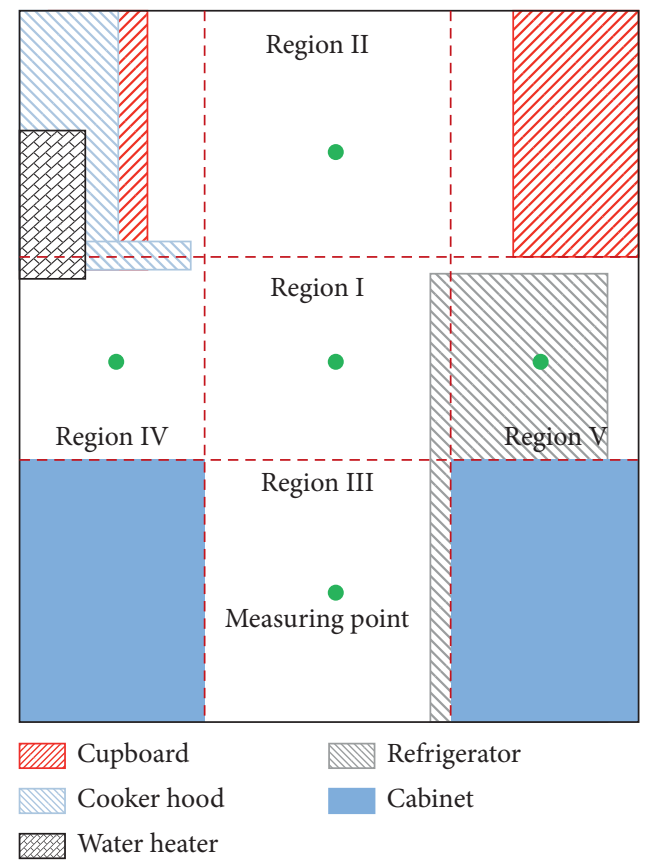

Figure 10: Division of congested room.

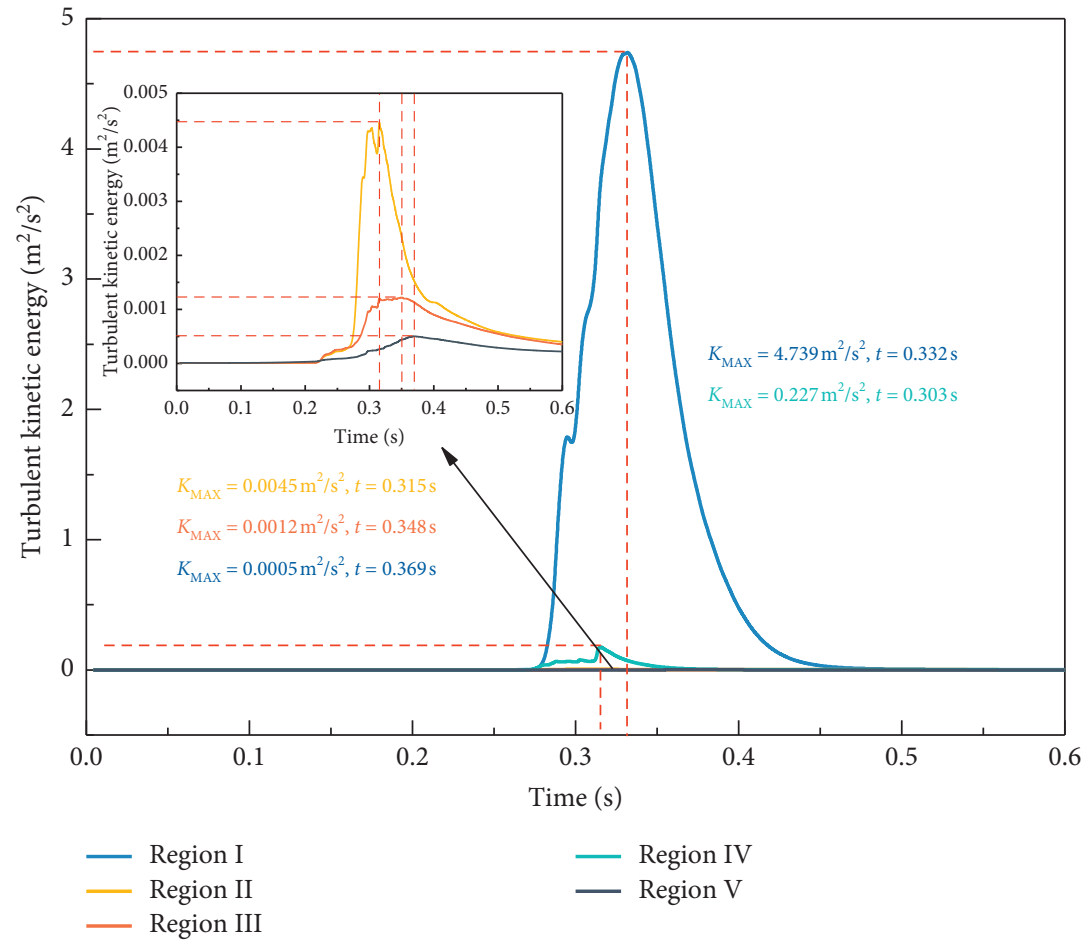

FIGURE 11: Turbulent kinetic energy-time curve at center position.

flow near the cooker hood is also observed in Figure 13(b). The turbulent flow in region $\mathrm{V}$ is hindered mainly by largescale congestion (refrigerator), and the turbulent flow is significantly weakened. The effect of congestion on turbulence is observed in two forms: promotion and hindrance. Small-scale congestion can generate stronger turbulent eddies and promote an increase in turbulent flow energy.
Large-scale congestion perpendicular to the direction of flame propagation affects turbulence; the obstructive effect is dominant. The arrangement of cupboards, cabinets, and other congestion along the flame propagation direction has little effect on indoor turbulence, which is consistent with the conclusions of Bjerketvedt et al. [31]. The difference in turbulence in different regions is also due to the influence of 


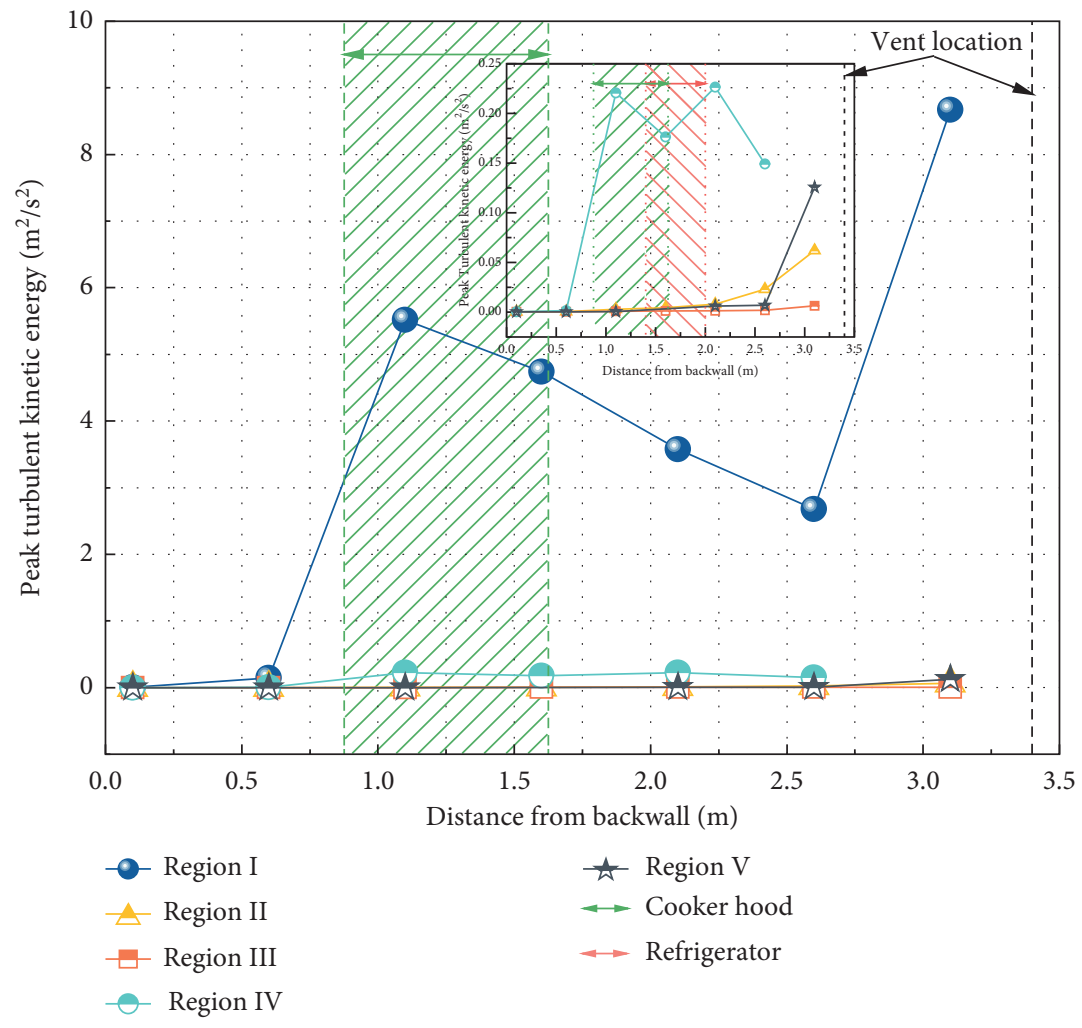

FIGURE 12: Indoor peak turbulent kinetic energy-distance curve.
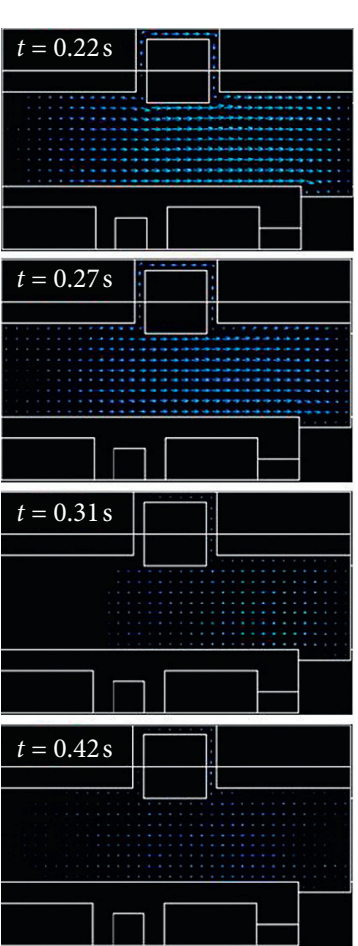

(a)
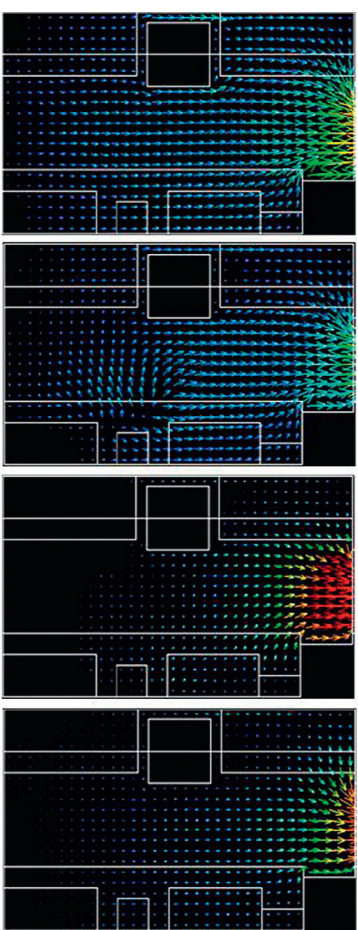

(b)

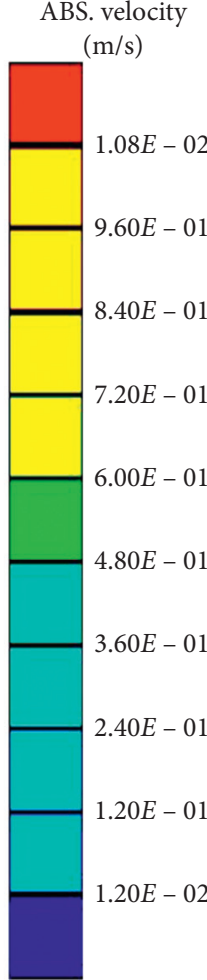

(c)

Figure 13: Flow velocity vector. (a) $z=0.4 \mathrm{~m}$. (b) $z=1.4 \mathrm{~m}$. (c) $z=2.1 \mathrm{~m}$. 


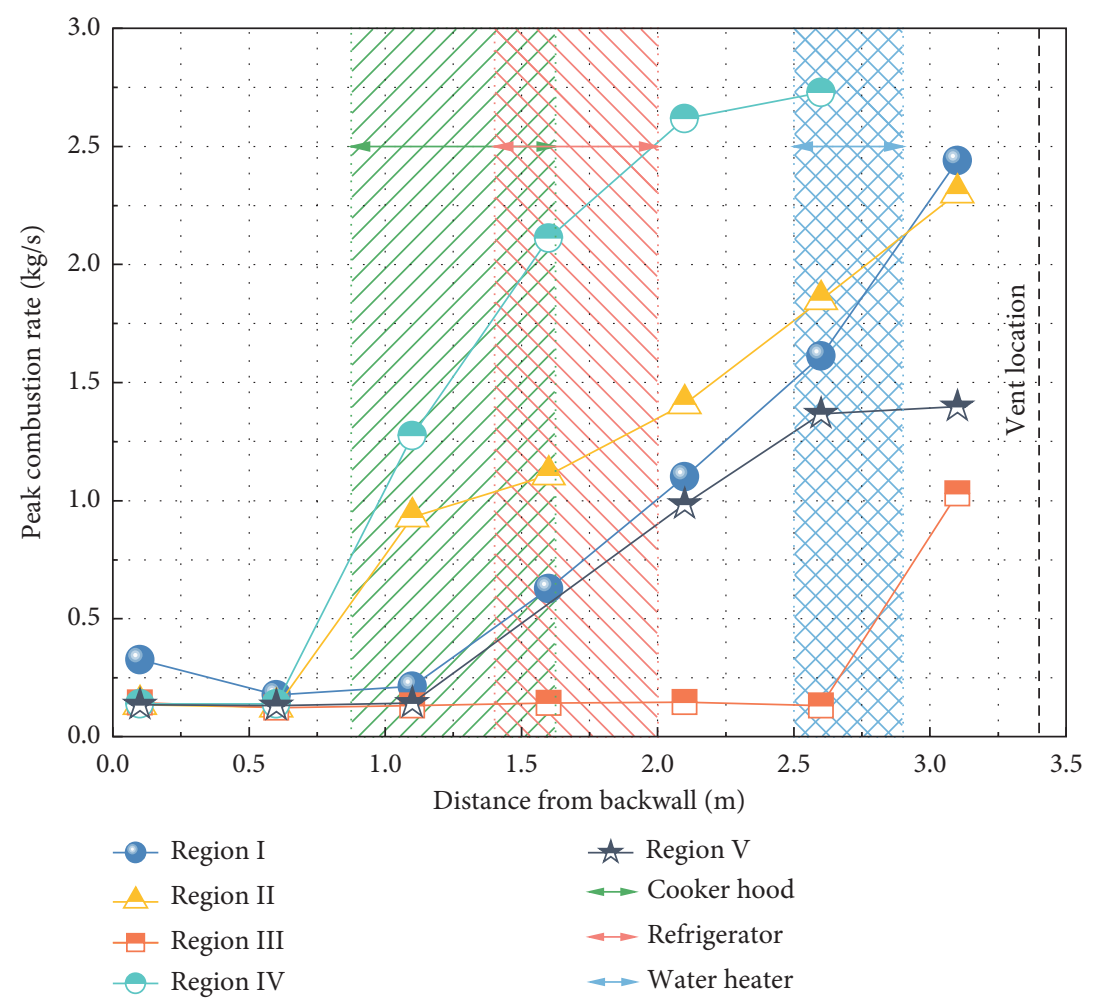

FIGURE 14: Indoor peak combustion rate-distance curves in five regions.

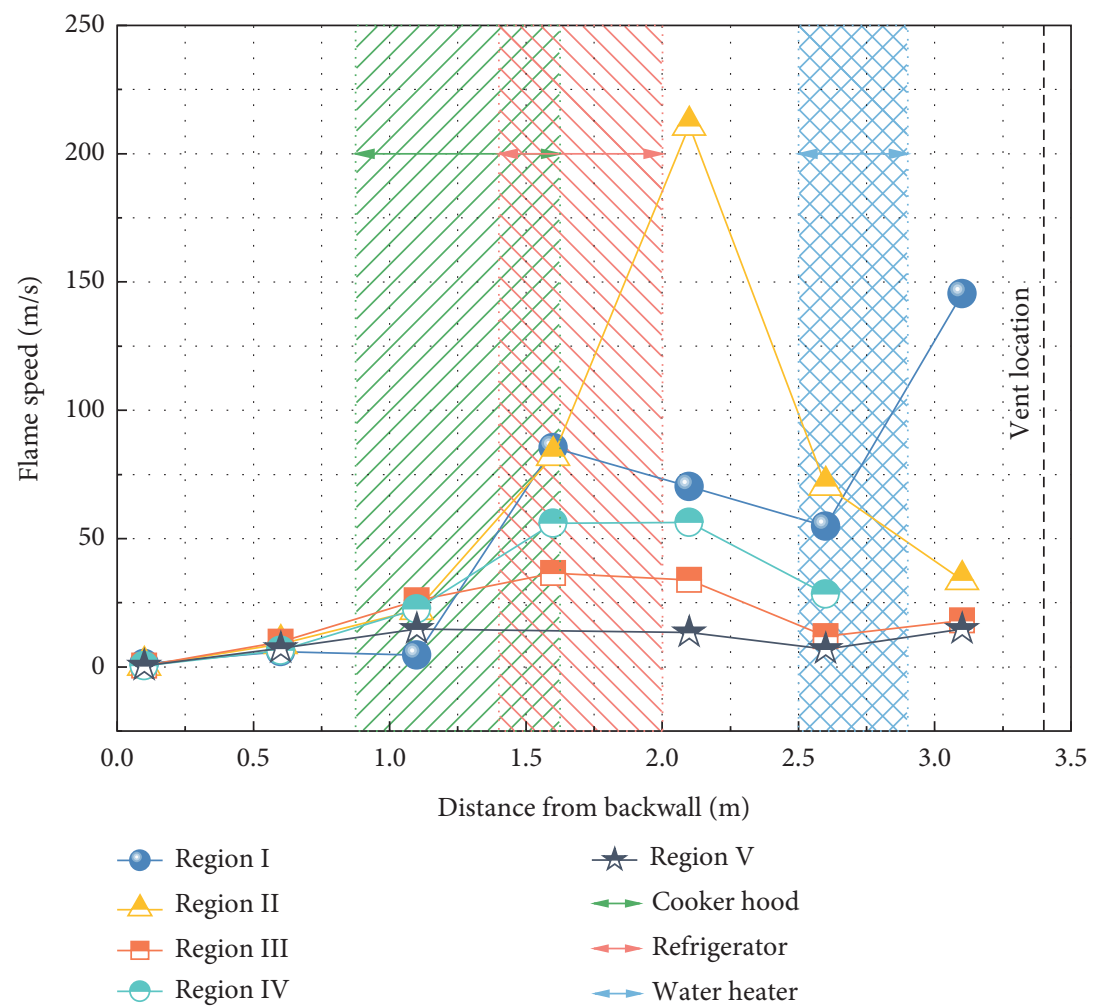

FIGURE 15: Indoor flame propagation speed-distance curves in five regions. 


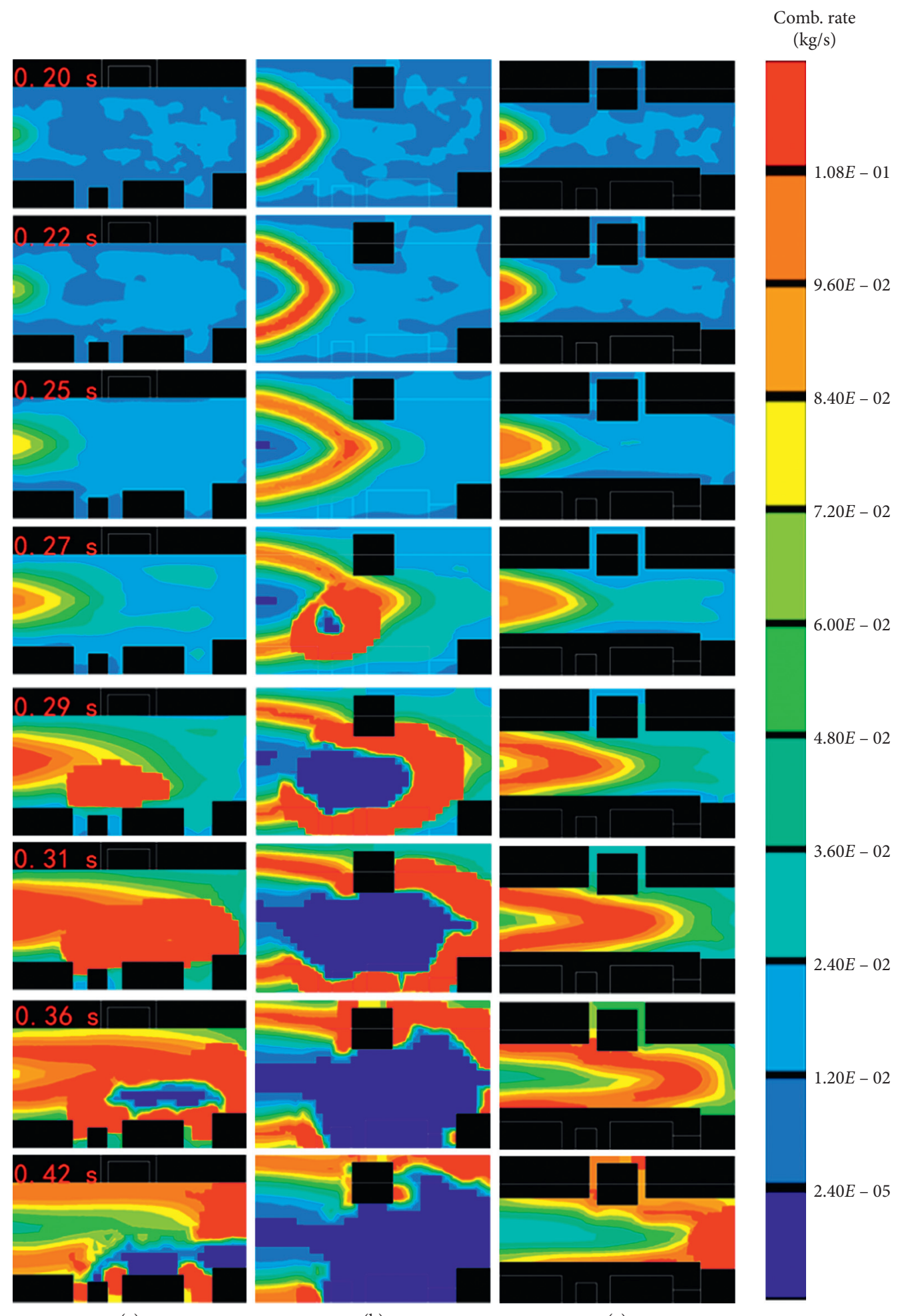

(a)

(b)

(c)

FIGURE 16: Flame cloud map on z slice. (a) $z=2.1 \mathrm{~m}$ (b) $z=1.4 \mathrm{~m}$ (c) $z=0.4 \mathrm{~m}$.

congestion on the volume of unburned gas. There is no congestion in region $I$, although the turbulence is the greatest, indicating that the influence of congestion on the flame is much stronger than on the volume of unburned gas [32].
4.2.2. Combustion Rate and Flame. Figure 14 shows the variation trend of the indoor peak combustion rate along the axial direction of the room. It is observed in the figure that the peak combustion rate in each region gradually increases with increasing distance, but the development trend is 


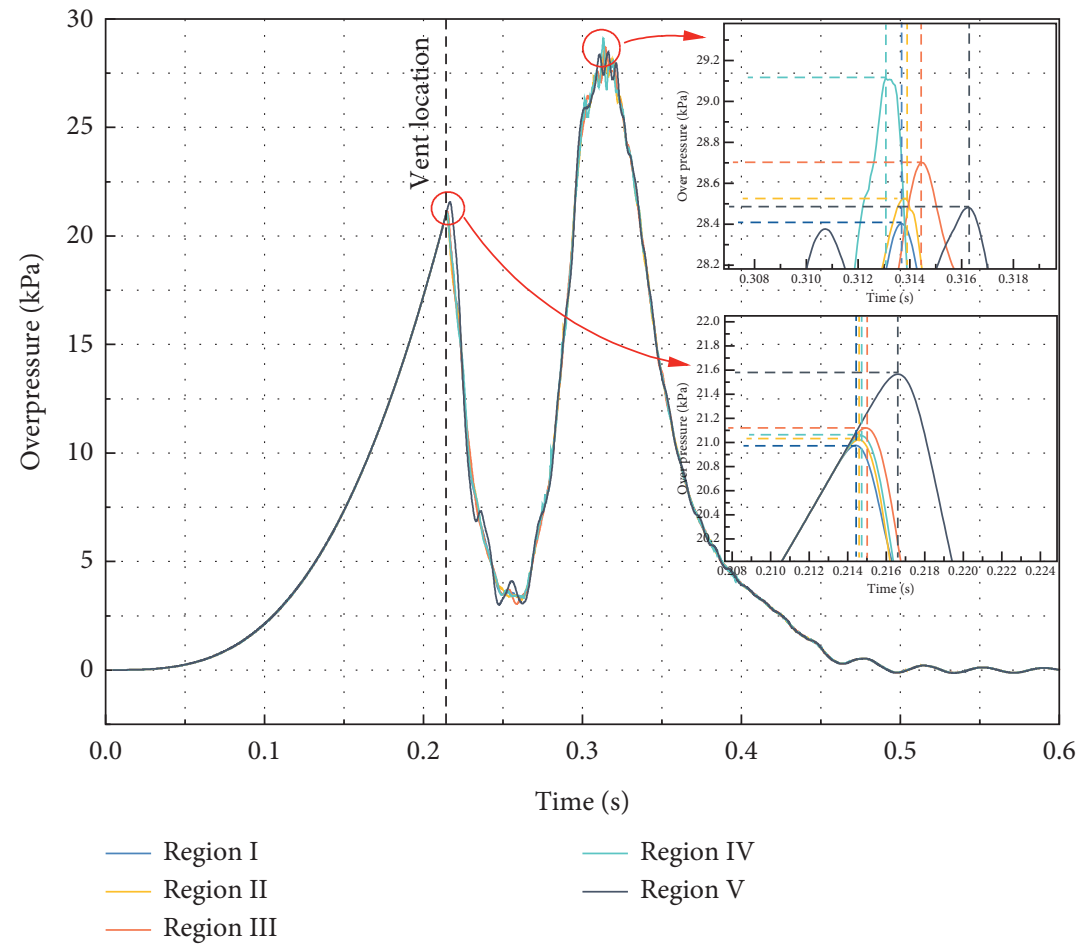

FIgURE 17: Overpressure-time curve of central measuring point in each region.

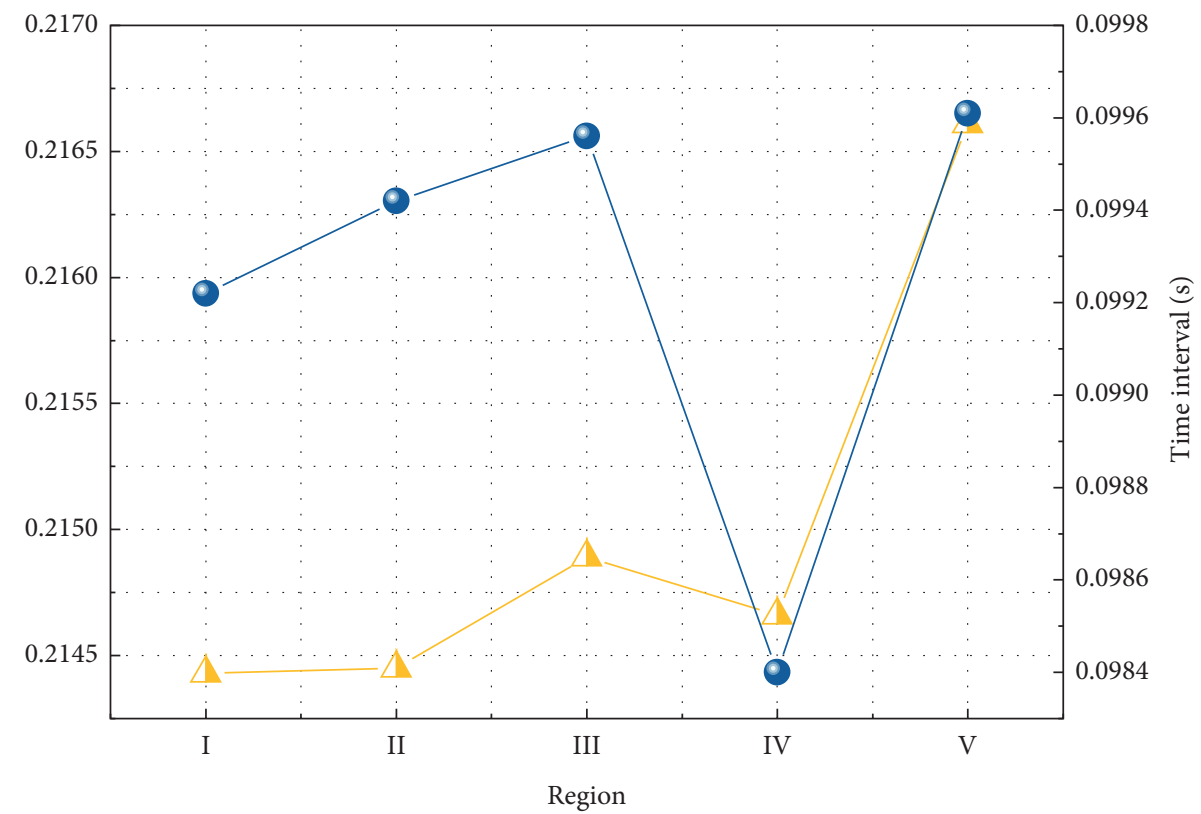

$-\Delta$ - Arrival time

-o- Time interval

Figure 18: Comparison of opening pressure arrival time and overpressure double-peak interval time in different regions under typical congestion conditions.

slightly different due to the influence of congestion, explosion vents, and the wall surface, manifesting mainly in different increase rates and initial increase points. Regions I and II are affected by the combination of explosion vents and small-scale congestion; the burning rate continues to increase and reaches a maximum at the explosion vents. Region III is affected mainly by the explosion vent and generally maintains a low combustion rate, increasing suddenly near the explosion vent. Region IV is promoted by the congestion, increasing first and maintaining a faster 


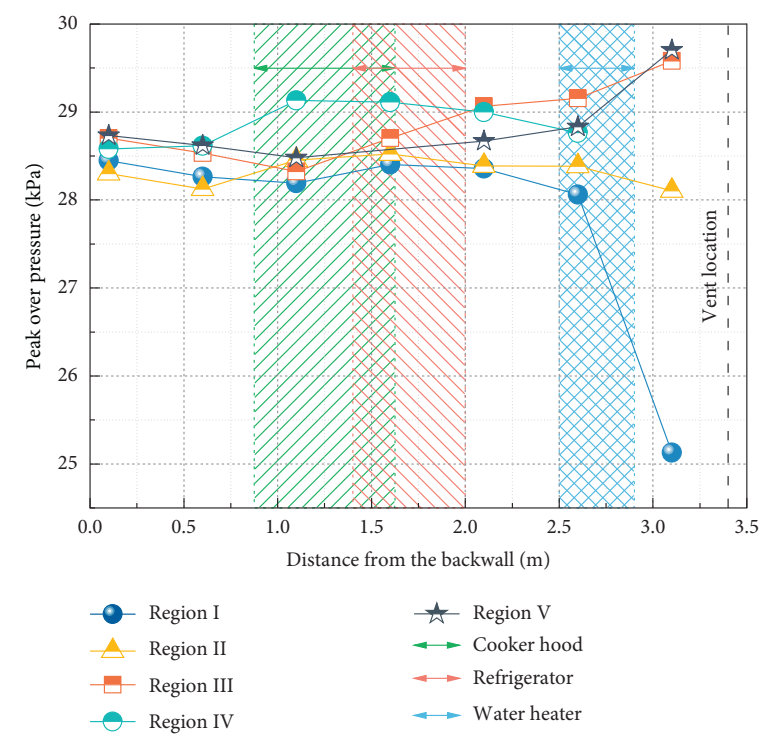

Figure 19: Peak overpressure-distance curve in each region.

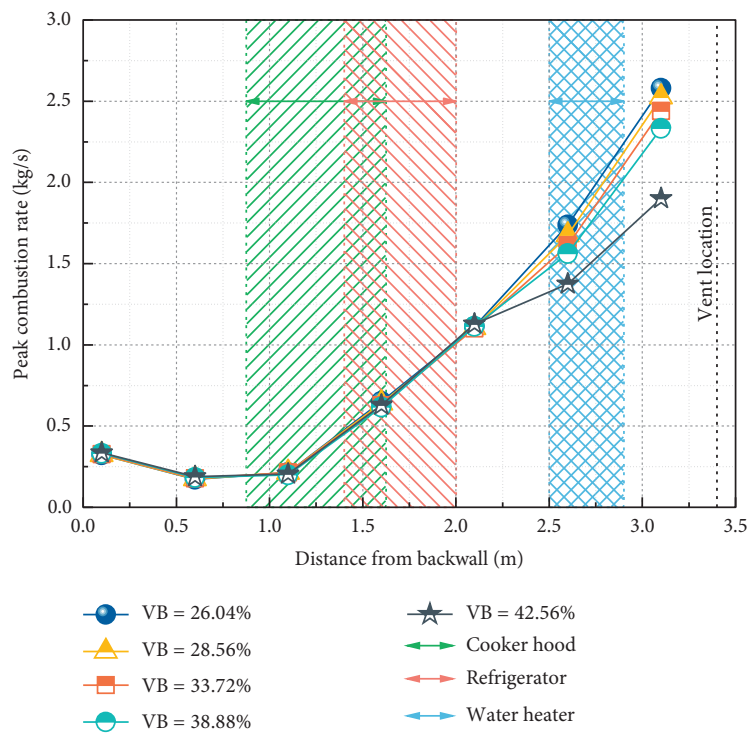

FIGURE 20: Indoor peak combustion rate-distance curve with different volume blockage.

increase. Region V is mainly obstructed by congestion, manifested by the relatively slow increase of the combustion rate.

The flame propagation speed along the length of the room is shown in Figure 15. The flame propagation speed first increases and then decreases with the distance. The increase in region II is the most obvious; the increase in region $\mathrm{V}$ is the slowest; region I has a secondary increase near the explosion vent. From analysis of the flame cloud maps on different height slices of the room, it is observed in Figure 16(a) that the flame reaches the vicinity of the cooker hood in approximately $290 \mathrm{~ms}$ at a vertical height of $2.1 \mathrm{~m}$ and is affected by small-scale congestion to produce a burning red ellipsoid area. It continues to increase, passing through multiple congestion objects; the flame velocity in region II has a large peak, but the flame propagation velocity near the explosion vent is blocked by the wall and rapidly decreases. Figure 16(c) shows the flame distribution at a vertical height of $0.4 \mathrm{~m}$. The congestion in this region is mainly a large cabinet arranged along the flame propagation direction, which has a small shearing effect on the flame; the flame grows slowly in region $\mathrm{V}$. The vertical height in Figure 16(b) is most affected by the explosion vent and is $1.4 \mathrm{~m}$ directly in front of its center. The turbulence near the vent causes a secondary increase in the flame velocity in region $\mathrm{I}$.

4.2.3. Overpressure. Figure 17 shows the overpressure-time curve of the indoor center measuring point. The trends of the overpressure time curve in each region are similar, but the $P_{1}$ and $P_{2}$ peaks on each curve and their arrival times 


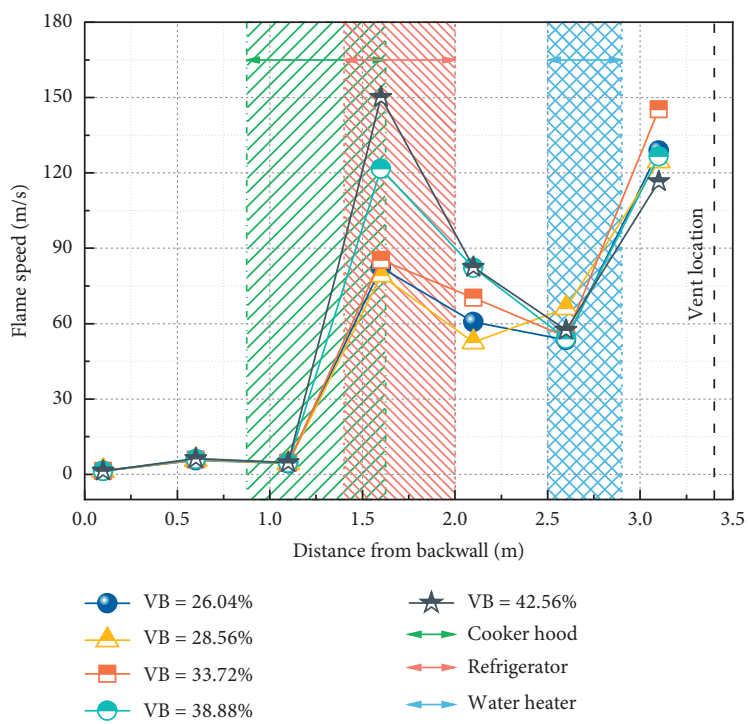

FIGURE 21: Indoor flame propagation speed-distance curve with different volume blockage.

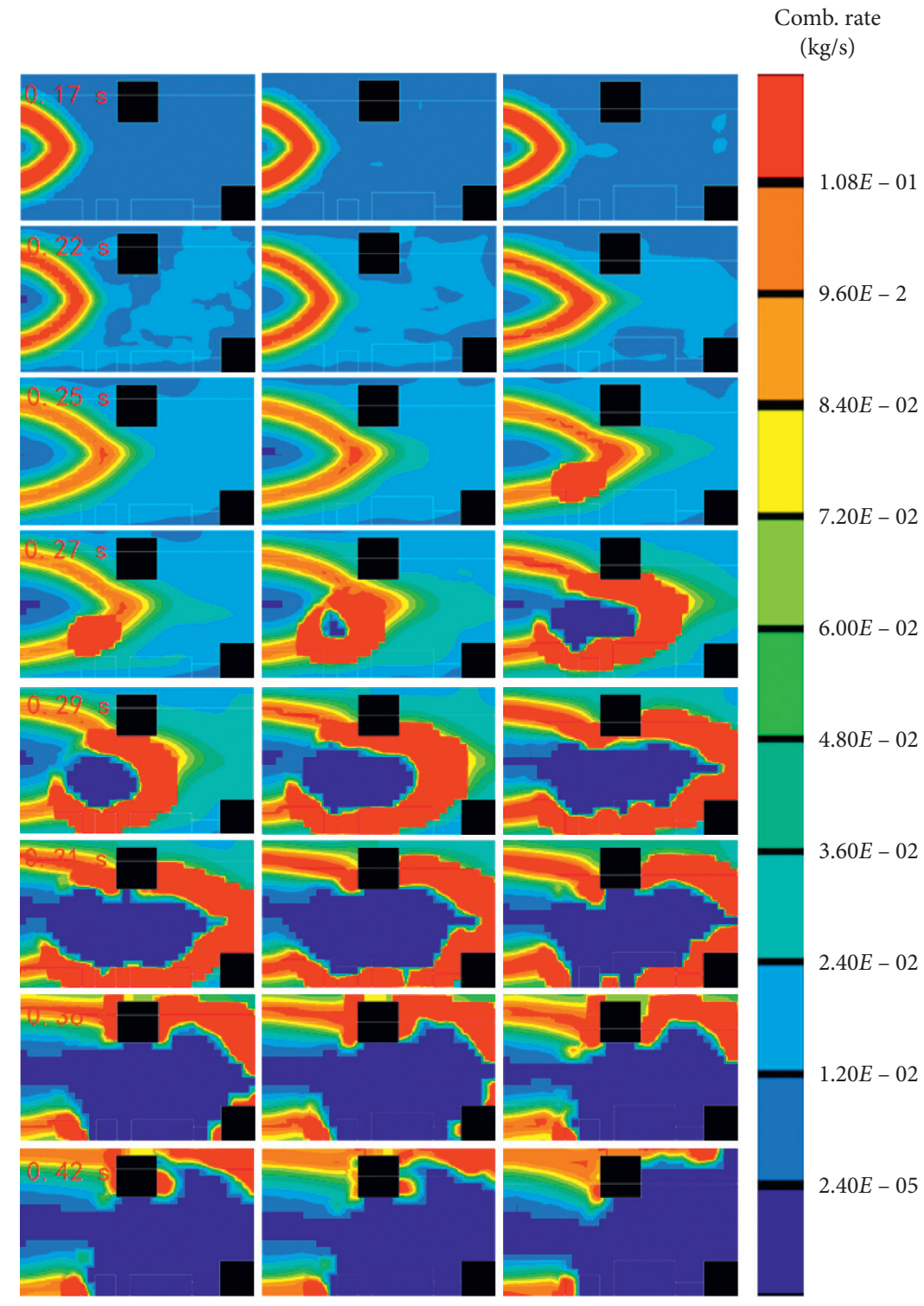

(a)

(b)

(c)

FIGURE 22: Flame cloud map on slices with a vertical height of $1.4 \mathrm{~m}$. (a) $26.04 \%$; (b) $33.72 \%$; (c) $42.56 \%$. 


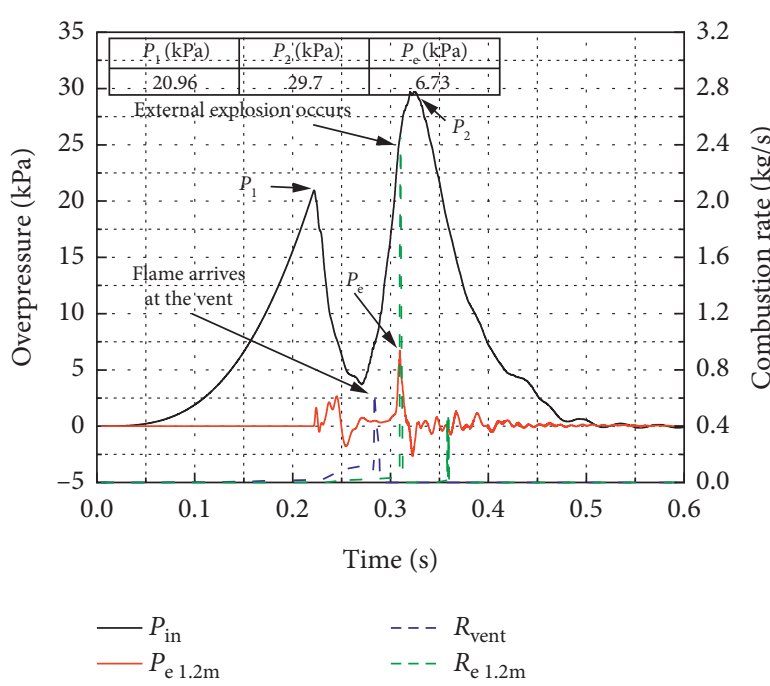

(a)

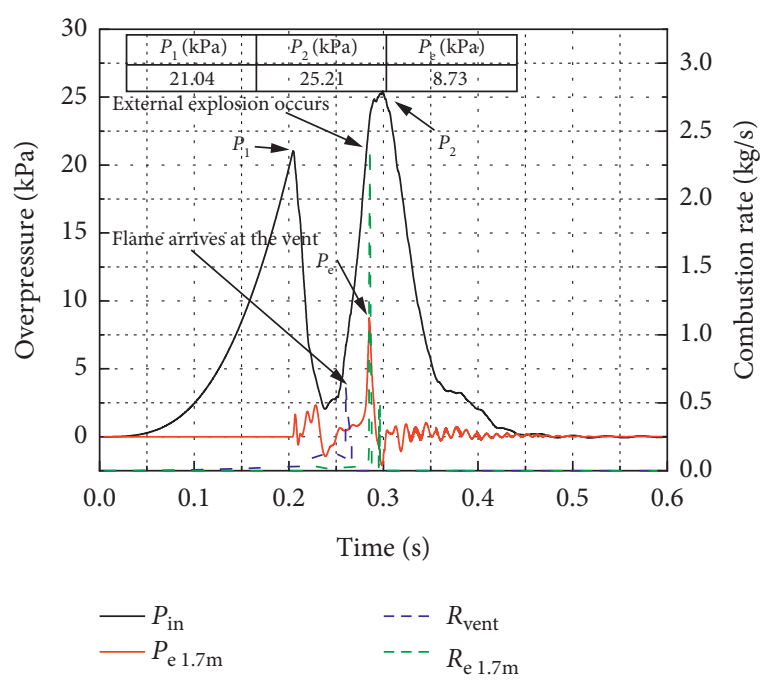

(b)

Figure 23: Overpressure-time and combustion rate-time curves at the center of the room with different volume blockages. (a) Volume blockage of $26.04 \%$. (b) Volume blockage of $42.65 \%$.

are slightly different, indicating that the congestion has an influence on the time and space distribution of the pressure field. Combining the opening pressure arrival time and the overpressure double-peak interval time in the five regions, as shown in Figure 18, it is found that region I, which is most affected by the turbulence of congestion in all directions, increases to the opening pressure first. However, after the explosion vent is opened, the peak overpressure $P_{2}$ in this region is the smallest. In region IV, with the most small-scale congestion, peak overpressure $P_{2}$ is the greatest; the interval between the double peaks of overpressure in this region is the shortest. Figure 19 shows the peak overpressure-distance curve on the central axis of the explosion vent. Similar to the development of the turbulent kinetic energy and combustion rate, region I is most affected by the explosion vent. Near the explosion vent, the peak overpressure decreases rapidly; region IV is most affected by small-scale congestion, and the peak overpressure increases slightly near the cooker hood.

\subsection{Effect of Volume Blockage on Explosion}

4.3.1. Peak Combustion Rate and Flame. Figures 20 and 21 show the curves of the peak combustion rate-distance and flame speed-distance on the central axis of the room with different volume blockages. It is observed in the figures that the peak combustion rate on the indoor axis shows an increasing trend with distance. The maximum peak combustion rate appears near the explosion vent and decreases with an increase in the volume blockage. The variation trend of the indoor flame propagation speed is similar to that of the turbulent kinetic energy; accelerated flame propagation occurs at the junction of the sudden change in the congestion cross-section and the small congestion and near the explosion vent. From analysis of the flame cloud map at a height of $1.4 \mathrm{~m}$ with different volume blockages in Figure 22, it is observed that because the flame development space decreases with an increase in volume blockage, the flame propagates to the two side walls faster in the first half and is constrained by the congestion. Forward propagation accelerates, thereby accelerating the effect of the cross-sectional mutation cabinet, small-scale cooker hood, and explosion vent on the propagation path, ultimately leading to faster flame propagation. In the second half, there may be more combustible gas in the room with a small volume blockage. An increase in the gas cloud released to the outside leads to a more violent external explosion. The explosion congestion causes more gas to burn in the room; the flame propagation speed fluctuates near the explosion vent, as shown in Figures 21 and 22.

4.3.2. Overpressure. Figure 23 shows the indoor and outdoor overpressure and combustion rate-time curves with different volume blockages. Figure 24 shows the maximum peak overpressure-distance curves on the central axis with five volume blockages. Figure 25 shows the curves of the opening pressure arrival time and double peak interval of the overpressure for different volume blockages. It is observed in the figure that with different volume blockages, the indoor overpressure curves all present a bimodal structure. Peak $P_{1}$ is essentially the same; its value is approximately equal to the opening pressure of $20 \mathrm{kPa}$, but its arrival time is earlier with an increase in the volume blockage. Peak $P_{2}$ is the maximum indoor peak. Generally, the distribution trend of the maximum indoor peak overpressure is essentially the same with different volume blockages, decreasing with an increase in volume blockage. The time between the overpressure double peaks decreases first and then increases with an increase in the volume blockage. It is observed in Figure 23 that external explosions occur with different volume blockages. With an increase in volume blockage, the peak outdoor overpressure is larger, and the peak indoor overpressure is smaller. 


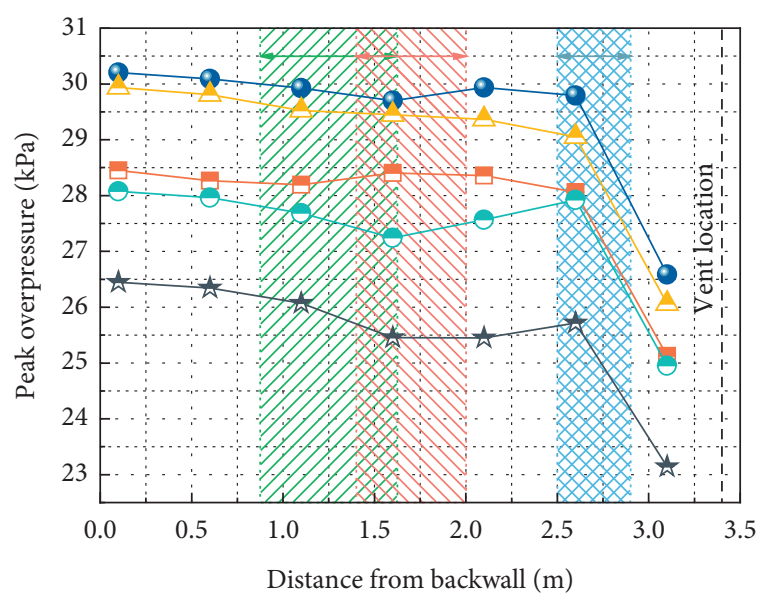

$$
\begin{array}{ll}
\multimap \mathrm{VB}=26.04 \% & \hookrightarrow \mathrm{VB}=42.56 \% \\
\triangle \mathrm{VB}=28.56 \% & \hookrightarrow \text { Cooker hood } \\
\square \mathrm{VB}=33.72 \% & \hookrightarrow \text { Refrigerator } \\
\multimap \mathrm{VB}=38.88 \% & \hookrightarrow \text { Water heater }
\end{array}
$$

FIgURE 24: Comparison of peak overpressure-distance curves with different volume blockages.

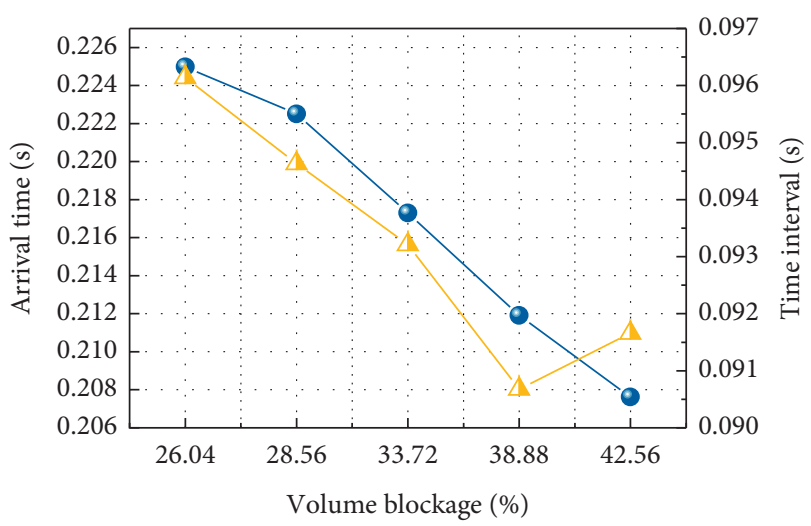

$$
\begin{aligned}
& \text { - - Arrival time } \\
& -\triangle \text { - Time interval }
\end{aligned}
$$

FIgURE 25: Comparison of opening pressure arrival time and overpressure double peak interval time with different volume blockages.

Although the increase in volume blockage reduces the combustible gas inside and outside, it increases the indoor flame propagation speed, which leads to a stronger external explosion. Peak $P_{2}$ did not increase with increased intensity of the external explosion. It may be that the maximum peak overpressure in the room results from the combined effects of the external explosion and the maximum flame area [33]. The flame development area in a room with a low volume blockage is larger, thus the peak indoor combustion rate and maximum peak overpressure are greater, as shown in Figures 20 and 24.

\section{Conclusion}

(1) The congestion and explosion vent have a synergistic effect on the explosion flow field. Opening explosion venting surfaces such as building doors and windows increases the indoor turbulent kinetic energy, combustion rate, and flame propagation speed to some extent, but the impact is small. A confinement explosion can significantly reduce the indoor peak overpressure. Compared with a vented explosion in an empty room, congestion objects of different scales such as furniture and home appliances significantly increase the turbulence, combustion rate, flame speed, and peak overpressure in a vented explosion room. All types of congestion in the kitchen and the explosion venting surface coordinate to increase the severity of natural gas explosion accidents.

(2) The indoor gas explosion flow field distribution is asymmetric under the action of congestion objects of different sizes and layouts. Small-scale congestion such as the lampblack machine in the kitchen promotes the formation of turbulence in the adjacent area and increases the flame propagation speed and combustion rate. Large-scale congestion such as a refrigerator arranged in the vertical flame propagation direction hinders the development of turbulence and flame propagation and reduces the combustion rate. Large-scale cabinets and cupboards arranged along the flame propagation direction have little influence on the indoor turbulence. The overpressure distribution in indoor regions is relatively balanced, mostly between 28 and $29 \mathrm{kPa}$. The explosion vent and its wall have a greater impact on the overpressure distribution.

(3) An increase in volume blockage from increased large-scale indoor congestion has a significant impact on the vented explosion process. Increasing the size of the congestion along the flame propagation direction promotes a change in the flame propagation mode and a sudden change in the congestion cross-section, leading to an increase in the flame propagation speed and acceleration of the increase in internal pressure. An external explosion is greater in a room with a high congestion rate. The indoor peak combustion rate and peak overpressure decrease as the volume blockage increases because there are more combustible gases in a room with low congestion and a larger flame area during complete combustion.

\section{Nomenclature}

$i$ : The coordinate directions

$j$ : The coordinate directions

K: $\quad$ Turbulent kinetic energy $\left(\mathrm{m}^{2} \cdot \mathrm{s}^{-2}\right)$

$x$ : The space coordinate

$t: \quad$ The time coordinate

$p$ : The static pressure

E: $\quad$ Energy (J) 
$C_{V}$ : The constant volume specific heat $(\mathrm{J} / \mathrm{kg} / \mathrm{K})$

$T: \quad$ Temperature (K)

$m_{\mathrm{fu}}$ : The fuel mass fraction

$H_{c}$ : Heat of combustion $(\mathrm{kJ} / \mathrm{mol})$

$C_{\mu}$ : Constant of $k-\varepsilon$ model $\left(\mathrm{m}^{2} / \mathrm{s}\right)$

$R_{\mathrm{fu}}$ : Volume combustion rate $\left(\mathrm{kg} / \mathrm{m}^{3} / \mathrm{s}\right)$

$R_{\text {min }}$ : Minimum mass fraction

$C_{t}$ : Combustion-model constant

$u$ : Velocity $(\mathrm{m} / \mathrm{s})$

$u_{t}$ : Turbulence intensity $(\mathrm{m} / \mathrm{s})$

$L_{t}$ : Turbulent length scale $(\mathrm{m})$

$S_{l}$ : Laminar combustion velocity $(\mathrm{m} / \mathrm{s})$

$R_{f}$. Spherical flame radius

$F_{s}$ : Laminar flame acceleration coefficient

$\Gamma^{*}: \quad$ Turbulent-diffusion coefficient $\left(\mathrm{m}^{2} / \mathrm{s}\right)$

$\tau_{i j}: \quad$ Viscous stress tensor

$\mu_{t}$ : Turbulence-viscosity coefficient

$\varepsilon: \quad$ Dissipation rate of turbulent kinetic energy $\left(\mathrm{m}^{2} / \mathrm{s}^{3}\right)$

$\delta_{i j}: \quad$ The Kronecker delta

$(\sigma)^{*}$ : Default value of the turbulent Prandtl constant

$v$ : $\quad$ Fluid dynamic viscosity $\left(\mathrm{m}^{2} / \mathrm{s}\right)$

$\rho: \quad$ Gas density $\left(\mathrm{kg} / \mathrm{m}^{3}\right)$.

\section{Data Availability}

The data that support the findings of this study are available from the corresponding author upon reasonable request.

\section{Conflicts of Interest}

The authors declare that they have no conflicts of interest.

\section{Acknowledgments}

The authors appreciate the financial support received from the Beijing Natural Science Foundation-Municipal Education Committee Joint Funding Project (No. KZ201910017020), the Training Funded Project of the Beijing Youth Top-Notch Talents of China (No. 2016000026833ZK05), Science and Technology Plan Project of Beijing Education Commission (No. KM202010017008), and the Training Funded Project of the Beijing Young Backbone Talents of China (No. 2018000020124G087). At last, the authors appreciate Elsevier for providing good English translation service for this paper.

\section{References}

[1] Chinagas, "Domestic gas safety accident analysis report in 2020," 2020, http://www.chinagas.org.cn/mobile/index.php/ $\mathrm{m} / \mathrm{c} / 5 / 6 / 54004$.

[2] P. Naamansen, D. Baraldi, B. H. Hjertager, T. Solberg, and S. Cant, "Solution adaptive CFD simulation of premixed flame propagation over various solid obstructions," Journal of Loss Prevention in the Process Industries, vol. 15, no. 3, pp. 189-197, 2002.

[3] M. Kuznetsov, A. Friedrich, G. Stern, N. Kotchourko, S. Jallais, and B. L'Hostis, "Medium-scale experiments on vented hydrogen deflagration," Journal of Loss Prevention in the Process Industries, vol. 36, pp. 416-428, 2015.
[4] Q. Zhang, Y. Wang, and Z. Lian, "Explosion hazards of LPGair mixtures in vented enclosure with obstacles," Journal of Hazardous Materials, vol. 334, pp. 59-67, 2017.

[5] Z. Lian and Q. Zhang, "Methods for estimating fragment hazard in gas explosion," Journal of Hazardous Materials, vol. 381, Article ID 120989, 2019.

[6] G. Tomlin, D. M. Johnson, P. Cronin, H. N. Phylaktou, and G. E. Andrews, "The effect of vent size and congestion in largescale vented natural gas/air explosions," Journal of Loss Prevention in the Process Industries, vol. 35, pp. 169-181, 2015.

[7] A. R. Masri, S. S. Ibrahim, N. Nehzat et al., "Experimental study of premixed flame propagation over various solid obstructions," Experimental Thermal and Fluid Science, vol. 21, no. 1-3, pp. 109-116, 2000.

[8] S. S. Ibrahim and A. R. Masri, "The effects of obstructions on overpressure resulting from premixed flame deflagration," Journal of Loss Prevention in the Process Industries, vol. 14, no. 3, pp. 213-221, 2001.

[9] A. R. Masri, S. S. Ibrahim, and B. J. Cadwallader, "Measurements and large eddy simulation of propagating premixed flames," Experimental Thermal and Fluid Science, vol. 30, no. 7, pp. 687-702, 2006.

[10] M. Schiavetti, T. Pini, and M. Carcassi, "The effect of venting process on the progress of a vented deflagration," International Journal of Hydrogen Energy, vol. 44, pp. 9080-9088, 2018.

[11] M. Schiavetti and M. Carcassi, "Maximum overpressure vs. $\mathrm{H} 2$ concentration non-monotonic behavior in vented deflagration. Experimental results," International Journal of $\mathrm{Hy}$ drogen Energy, vol. 42, no. 11, pp. 7494-7503, 2017.

[12] T. Skjold, H. Hisken, S. Lakshmipathy et al., "Vented hydrogen deflagrations in containers: effect of congestion for homogeneous and inhomogeneous mixtures," International Journal of Hydrogen Energy, vol. 44, no. 17, pp. 8819-8832, 2019.

[13] Y. Chen, Z. Li, C. Ji, and X. Liu, "Effects of hydrogen concentration, non-homogenous mixtures and obstacles on vented deflagrations of hydrogen-air mixtures in a $27 \mathrm{~m} 3$ chamber," International Journal of Hydrogen Energy, vol. 45, no. 11, pp. 7199-7209, 2020.

[14] H. Li, Z. Tang, J. Li, J. Guo, J. Zhang, and Q. Li, "Investigation of vented hydrogen-air deflagrations in a congested vessel," Process Safety and Environmental Protection, vol. 129, pp. 196-201, 2019.

[15] D. L. Mazza, L. Giordano, P. Castaldo, and D. Gino, “Assessment of the efficiency of seismic design for structural robustness of RC structures," International journal of earthquake engineering, vol. 34, no. 3-4, pp. 63-77, 2017.

[16] NFPA68, "Technical committee on explosion protection systems," Standard on Explosion protection by Deflagration Venting, NFPA, Quincy, MA, USA, 2013.

[17] EN14994, "Technical committee FSH/23, fire precautions in industrial and chemical plant," Gas Explosion Venting Protective Systems, BSI, London, UK, 2007.

[18] GB 50016, Code for Fire Protection Design of Buildings, Ministry of Housing and Urban-Rural Development of the People's Republic of China, Beijing, China, 2018.

[19] K. Yang, P. F. Lv, Q. R. Hu et al., "Research on synergetic effect of large-scale obstacles and explosion vents on indoor explosion of natural gas," Journal of Safety Science and Technology, vol. 14, no. 12, pp. 21-27, 2018.

[20] S. Zhang and Q. Zhang, "Effect of vent size on vented hydrogen-air explosion," International Journal of Hydrogen Energy, vol. 43, no. 37, Article ID 17788, 2018. 
[21] L. Pang, Q. Zhang, W. Li, C. Xiang, and R. M. Tan, "Relationship between shock wave and high-temperature flow produced by gas explosion in coal mine roadways," Chinese Journal of High Pressure Physics, vol. 25, pp. 457-462, 2011.

[22] L. Pang, Q. Hu, M. Jin, and K. Yang, "Effect of congestion on flow field of vented natural gas explosion in a kitchen," Advances in Civil Engineering, vol. 2021, no. 1-3, 22 pages, Article ID 6671875, 2021.

[23] C. R. Bauwens, J. Chaffee, and S. B. Dorofeev, "Vented explosion overpressures from combustion of hydrogen and hydrocarbon mixtures," International Journal of Hydrogen Energy, vol. 36, no. 3, pp. 2329-2336, 2011.

[24] B. Angers, A. Hourri, P. Benard, E. Demaël, S. Ruban, and S. Jallais, "Modeling of hydrogen explosion on a pressure swing adsorption facility," International Journal of Hydrogen Energy, vol. 39, no. 11, pp. 6210-6221, 2014.

[25] GB 50096, Design Code for Residential Buildings, Ministry of Housing and Urban-Rural Development of the People's Republic of China, Beijing, China, 2011.

[26] 14J913-2, National Building Standard Design Atlas-Residential Kitchen, China Institute of Building Standard Design \& Research, Beijing, China, 2014.

[27] X. Wen, M. Yu, W. Ji, M. Yue, and J. Chen, "Methane-air explosion characteristics with different obstacle configurations," International Journal of Mining Science and Technology, vol. 25, no. 2, pp. 213-218, 2015.

[28] X. Wen, M. Yu, Z. Liu, G. Li, W. Ji, and M. Xie, "Effects of cross-wise obstacle position on methane-air deflagration characteristics," Journal of Loss Prevention in the Process Industries, vol. 26, no. 6, pp. 1335-1340, 2013.

[29] C. Johansen and G. Ciccarelli, "Visualization of the unburned gas flow field ahead of an accelerating flame in an obstructed square channel," Combustion and Flame, vol. 156, no. 2, pp. 405-416, 2009.

[30] L. Pang, Q. Hu, J. Zhao, P. Lv, S. Sun, and K. Yang, "Numerical study of the effects of vent opening time on hydrogen explosions," International Journal of Hydrogen Energy, vol. 44, no. 29, Article ID 15689, 2019.

[31] D. Bjerketvedt, J. R. Bakke, and K. van Wingerden, "Gas explosion handbook," Journal of Hazardous Materials, vol. 52, no. 1, pp. 1-150, 1997.

[32] K. Zhang, Z. Wang, L. Ni, Y. Cui, Y. Zhen, and Y. Cui, "Effect of one obstacle on methane-air explosion in linked vessels," Process Safety and Environmental Protection, vol. 105, pp. 217-223, 2017.

[33] C. Xu, L. Cong, Z. Yu, Z. Song, and M. Bi, "Numerical simulation of premixed methane-air deflagration in a semiconfined obstructed chamber," Journal of Loss Prevention in the Process Industries, vol. 34, no. 1, pp. 218-224, 2015. 